Working Paper/Document de travail 2012-29

\title{
Efficiency and Bargaining Power in the Interbank Loan Market
}

by Jason Allen, James Chapman, Federico Echenique and Matthew Shum 
Bank of Canada Working Paper 2012-29

September 2012

\section{Efficiency and Bargaining Power in the Interbank Loan Market}

by

Jason Allen, ${ }^{1}$ James Chapman, ${ }^{1}$ Federico Echenique ${ }^{2}$ and Matthew Shum ${ }^{2}$

1Financial Stability Department

Bank of Canada

Ottawa, Ontario, Canada K1A 0G9

jallen@bankofcanada.ca

jchapman@bankofcanada.ca

2Division of the Humanities and Social Sciences

California Institute of Technology

fede@caltech.edu

mshum@caltech.edu

Bank of Canada working papers are theoretical or empirical works-in-progress on subjects in economics and finance. The views expressed in this paper are those of the authors.

No responsibility for them should be attributed to the Bank of Canada. 


\section{Acknowledgements}

We thank the Canadian Payments Association. We thank Lana Embree, Matthias Fahn, Rod Garratt, Denis Gromb, Scott Hendry, Thor Koeppl, Antoine Martin, Mariano Tappata, and James Thompson as well as seminar participants at the University of Western Ontario, Renmin University of China, the Bank of Canada workshop on financial institutions and markets, the FRBNY, and IIOC (Arlington) for comments. Any errors are our own. 


\begin{abstract}
Using detailed loan transactions-level data we examine the efficiency of an overnight interbank lending market, and the bargaining power of its participants. Our analysis relies on the equilibrium concept of the core, which imposes a set of no-arbitrage conditions on trades in the market. For Canada we show that while the market is fairly efficient, some degree of inefficiency persists throughout our sample. The level of inefficiency matches distinct phases of both the Bank of Canada's operations as well as phases of the 20072008 financial crisis, where more liquidity intervention implies more inefficiency. We find that bargaining power tilted sharply towards borrowers as the financial crisis progressed, and towards riskier borrowers. This supports a nuanced version of the TooBig-To-Fail story, whereby participants continued to lend to riskier banks at favorable rates, not because of explicit support to the riskier banks provided by governmental authorities, but rather due to the collective self-interest of these banks.
\end{abstract}

JEL classification: C71, G21, G28, E58

Bank classification: Financial institutions; Payment, clearing, and settlement systems

\title{
Résumé
}

À l'aide de données détaillées sur les transactions relatives aux prêts, les auteurs examinent l'efficience du marché du financement interbancaire à un jour ainsi que le pouvoir de négociation de ses participants. L'analyse repose sur ce concept d'équilibre qu'est le cœur, qui impose un ensemble de conditions de non-arbitrage aux opérations du marché. L’étude montre que même si, au Canada, ce marché fonctionne de façon efficace, il se caractérise par un certain degré d’inefficience tout au long de la période considérée. Les variations du degré d’inefficience correspondent à des phases distinctes tant des opérations de la Banque du Canada que de la crise financière de 2007-2008, des injections accrues de liquidité ayant pour corollaire une plus grande inefficience. Les auteurs constatent par ailleurs que la balance du pouvoir de négociation a penché très nettement durant la crise du côté des institutions emprunteuses, en particulier du côté des emprunteurs à risque. Cela tend à confirmer une version nuancée d'une hypothèse bien connue, à savoir que l'État vole au secours des banques en difficulté lorsque celles-ci sont trop grosses ou trop complexes (too big to fail). Selon cette version, les participants auraient continué d'octroyer des prêts à taux favorables aux banques à risque, non du fait d'un soutien explicite des autorités à ces banques, mais surtout parce que cet octroi était dans l'intérêt collectif des prêteurs.

Classification JEL : C71, G21, G28, E58

Classification de la Banque : Institutions financières; Systèmes de paiement, de compensation et de règlement 


\section{Introduction}

Multilateral trading markets are endemic in modern economies with well-known examples such as the bargaining over tariffs and similar trade barriers among the WTO countries, monetary and fiscal policy-making among the European Union countries, co-payment rate determination among hospital and insurance company networks, and even trades of players among professional sports teams. Our paper presents a novel approach to empirically assess the efficiency of these markets, and the bargaining power of the different agents in the market. We use data from the Canadian market for overnight loans.

A serious impediment to the analysis of efficiency and bargaining power in real-world trading environments is the complexity of the markets themselves. The players are engaged in a complicated game of imperfect competition, in which some of their actions are restricted by trading conventions, but where the players may communicate and send signals in arbitrary ways. Even if we could write down a formal model that would capture the interactions among players, it would be difficult to characterize the equilibrium of such a game - a prerequisite to any analysis of bargaining and efficiency. Moreover, the outcome of such a game greatly depends on the assumed extensive-form. For example, outcomes can vary according to the sequencing of offers (who is allowed to make an offer to whom and when), as well as the nature of information asymmetries among the players. For these reasons, a complete "structural" analysis of such imperfectly competitive bargaining environments seems out of the question.

In this paper we take a different approach. Instead of modeling the explicit multilateral trading game amongst market participants, we impose an equilibrium assumption on the final outcome of the market. Our approach is methodologically closer to general equilibrium theory than to game theory: We use the classical equilibrium concept of the core. The core simply imposes a type of ex-post no-arbitrage condition on observed outcomes; it requires that the outcome be immune to defection by any subset of the participating players. Many alternative equilibrium concepts would imply outcomes in the core, but the advantage for our purposes is that the core is "model free," in the sense that it does not require any assumptions on the extensive-form of the game being played. As we shall see, the relatively weak restrictions of the core concept nevertheless allow us to draw 
some sharp conclusions about how efficiently the Canadian overnight interbank market functioned, in the years preceding, and during, the most recent economic crisis.

Subsequently, for outcomes which are in the core, we define a simple measure of how much the observed outcomes favor particular market participants: specifically, borrowing versus lending banks in the overnight interbank market. We use this measure as an indicator of bargaining power, and analyze its relationship to characteristics of the market and its participants. Thus, in our paper efficiency means the degree to which the absence of arbitrage conditions imposed by the core are satisfied, and bargaining power results from the position of the outcomes in the core. If the outcome is relatively more favorable to some agents, we shall say that these agents have enjoyed greater bargaining power.

We study the Large Value Transfer System (LVTS) in Canada, which is the system the Bank of Canada uses to implement monetary policy. Throughout the day, LVTS participants send each other payments and at the end of the day have the incentive to settle their positions to zero. If there are any remaining short or long positions after interbank negotiations these must be settled with the central bank at unfavorable rates. Participants are therefore encouraged to trade with each other in the overnight loan market. This market is ideal for study for various reasons: first, the market operates on a daily basis among seasoned players, so that inexperience or naïvete of the players should not lead to any inefficiencies. Second, there is a large amount of detailed data available on the amount and prices of transactions in this market. Finally, the LVTS is a "corridor" system, meaning that interest rates in the market are bounded above and below, respectively, by the current rates for borrowing from and depositing at the central bank. This makes it easy to specify the outside options for each market participant, which is a crucial component in defining the core of the game; at the same time, the corridor leads to a simple and intuitive measure of bargaining power between the borrowers and lenders in the market. ${ }^{1}$

Several researchers have explicitly modeled the decision of market participants in environments similar to LVTS. For example, Ho and Saunders (1985), Afonso and Lagos (2011), Duffie and Gârleanu (2005), and Duffie, Gârleanu, and Pedersen (2007) examine the efficiency of the allocation

\footnotetext{
${ }^{1}$ In contrast, in overnight markets without such an explicit corridor, both the outside options and bargaining power are not as convenient to define. Many central banks use a corridor system - e.g. the ECB. The Federal Reserve and Bank of Japan, however, use reserve regimes. Corridor system rely on standing liquidity facilities whereas reserve regimes rely on period-average reserve requirements. See Whitsell (2006) for a discussion.
} 
of funds in the Federal funds market or over-the-counter markets, more generally. ${ }^{2}$ The systems, markets and agents under study in this paper have previously been examined in Chapman, McAdams, and Paarsch (2007), Hendry and Kamhi (2009), Bech, Chapman, and Garratt (2010), and Allen, Hortaçsu, and Kastl (2011).

Moreover, as previously mentioned, the core imposes, essentially, no-arbitrage conditions on the trades in the interbank market, so that inefficient outcomes - those which violate the core conditions - are also those in which arbitrage opportunities were not exhausted for some coalition of the participating banks. Thus, our analysis of the interbank market through the lens of the the core complements a recent strand in the theoretical finance literature exploring reasons for the existence and persistence of "limited arbitrage" in financial markets (see Gromb and Vayanos (2010) for a survey of the literature).

A market outcome is the result of overnight lending between financial institutions at the end of the day: the outcome consists of the payoffs to the different banks. We (1) check if each outcome is in the core (this can be done by simply checking a system of inequalities), and (2) measure the degree to which outcomes are aligned with the interests of net borrowers or lenders in the system: our measure of bargaining power. We proceed to outline our results.

In the "normal" pre-crisis period, 2004-2007, the system largely complies with the core: it is efficient and there are few deviations from the absence of arbitrage. The bargaining power measure generally hovers around 0.5 , meaning that borrowers and lenders are equally favored. During periods when the risk prospects of borrowing banks rise above average, our bargaining power favors the lender, meaning that a lender can command higher interest rates if it lends to banks in riskier circumstances.

With the onset of the crisis in 2008, however, interesting changes happen. There is generally an increase in the number of violations of the core, so that the market becomes less efficient (in absolute terms, though, the inefficiencies are never very large). During the financial crisis the Bank of Canada increased its injections of cash settlement balances (similar to excess reserves). We find that these injections are positively correlated with violations of the core. The additional cash may have caused some situations where arbitrage opportunities were left unexploited.

\footnotetext{
${ }^{2}$ An interested reader can find a book length treatment of the economics of OTC markets in Duffie (2012).
} 
Also, the financial crisis brought about a shift in bargaining power to favor the borrowers; indeed, increased levels of risk are associated with changes in bargaining power to favor borrowers. That is, during the crisis period, when a borrowing bank (on the short side in the interbank market) becomes riskier according to standard measures of counterparty risk (including Merton's (1974) "distance to default" measure, credit default swap (CDS) prices, and exposure to wholesale funding), it receives better terms in the interbank loans market. All these results contrast sharply with our findings for the "normal" non-crisis period.

The needs for funds during the crisis should, as one might expect, have favored the lenders. Instead, we see borrowers obtaining better terms, and (surprisingly) a positive correlation between borrowers' bargaining power and market measures suggesting increasing default risk. In turn, we find that more core violations are associated with higher bargaining power for the borrowers.

Our findings may reflect an attempt by the system to shore up troubled banks: a "too big to fail" story. Our evidence is consistent with lenders being more lenient with borrowers, and in particular with the borrowers who were subject to higher levels of risk (be it at the level of the individual bank, or the system). The additional core violations during the crisis is also consistent with banks being less concerned with exploiting arbitrage opportunities and more with keeping the system whole to their mutual benefit.

Our findings, however, are more nuanced that the standard TBTF story, where financial institutions are so large and interconnected that if they encounter difficulty they would require government support. Overall, our findings are consistent with a "weak" version of the too-big-to-fail (TBTF) hypothesis, whereby banks within the Canadian overnight market continued to lend to risky counterparties despite the increasing risk in the market. However, such actions were not directly supported or guaranteed by regulators, as would be the case under the government-sponsored TBTF hypothesis; indeed, unlike in the U.S., no bail-outs or other forms of support were ever mentioned or undertaken in the Canadian financial sector. Rather, the observed effects appear to be a spontaneous reaction among the players in the market, and support the sentiment of then-governor of the Bank of Canada David Dodge, who stated that "we have a collective interest in the whole thing (sic [the Canadian financial system]) not going into a shambles."

There are several reasons why banks might be more concerned about the failure of other banks. 
One reason is that mark-to-market accounting and bank interconnectedness means that some banks were concerned with their positions vis-á-vis the riskier banks (e.g. Bond and Leitner (2010)). The short-term cost of lending to a risky interconnected bank at a discount might be far less than the cost of having to mark down assets linked to a failed institution.

At the same time, we also show that banks bounce bank and forth frequently between lending and borrowing in the interbank market. This fact, coupled with the repeated interaction which characterize the Canadian interbank market, may have led an outcome whereby lending banks refrain from exploiting borrowers during difficult times, instead lending to them at favorable rates under the consideration that such benevolent behavior may be reciprocated in the future when the banks find themselves on opposite sides of the market. This interpretation of our results is consistent with Carlin, Lobo, and Viswanathan's (2007) model of "apparent liquidity" in oligopolistic lending markets. Acharya, Gromb, and Yorulmazer (2012) construct a model in which "strong" banks exercise market power over "weak" banks which do not have other non-central bank outside options. Our findings suggest, to the contrary, that stronger lending banks appear to refrain from exercising market power over weaker borrowers.

Of course, the TBTF hypothesis has been widely discussed and circulated in both the academic (O'Hara and Shaw (1990), Rochet and Tirole (1996), Flannery (2010)) and nonacademic financial press (Sorkin (2009), Krugman (2010)). As far as we are aware, this paper presents some of the first quantitative evidence of such a hypothesis.

The remainder of the article is organized as follows. Section 2 presents the data. Section 3 discusses the methodology, both conceptually and how we implement it using the Canadian overnight interbank lending market. Section 4.3 presents the results while section 5 discusses their economic significance. Section 6 concludes.

\section{The Canadian Large Value Transfer System (LVTS)}

The primary data for our analysis comes from daily bank transactions observed in Canada's Large Value Transfer System (LVTS). LVTS is Canada's payment and settlement system and it is operated by the Canadian Payment Association. Similar to CHAPS in the United Kingdom, LVTS is a tiered 
system, unlike Fedwire in the United States. That is, there are a small number of direct participants and a larger number of indirect participants. ${ }^{3}$ There are currently 15 direct participants in LVTS. These are the Big 6 Canadian banks (Banque Nationale, Bank of Montreal, Bank of Nova Scotia, Canadian Imperial Bank of Commerce, Royal Bank of Canada, Toronto-Dominion Bank), HSBC, ING Canada, Laurentian Bank, State Street Bank, Bank of America, BNP Paribas, Alberta Treasury Branches, Caisse Desjardins, and a credit union consortium (Central 1 Credit Union). State Street joined LVTS in October 2004 and ING joined in October 2010.

Throughout the day payments are sent back-and-forth between direct participants. Like real-time gross settlement systems (RTGS), finality of payment sent through LVTS is in real-time; however, settlement in LVTS occurs at the end of the day. Relative to a RTGS system, the LVTS system has higher cost for survivors given default, but also substantial cost savings since banks do not need to post as much collateral. This is because most transactions in Canada are sent via a survivors pay, or partially collateralized, tranche. The cost of a partially collateralized system is an increase in counterparty risk. Participants manage counterparty risk by setting bilateral credit limits at the beginning of each day and also manage these limits throughout the day. ${ }^{4}$ Allen, Hortaçsu, and Kastl (2011) find, however, that even during the financial crisis direct participants did not lower their credit limits. They take this as evidence that there was no meaningful increase in counterparty risk in the payments system during the crisis.

\subsection{Data Description}

We are interested in studying the price and quantity of interbank overnight loans. Our period of analysis is April 1, 2004 to April 17, 2009. As flows in LVTS are not classified explicitly as either a payment or a loan, we follow the existing literature (eg. Acharya and Merrouche (2009), Afonso, Kovner, and Schoar (2011), and Allen, Hortaçsu, and Kastl (2011)) and use the Furfine algorithm (Furfine (1999)) to extract transactions which are most likely to be overnight loans, among the thousands of daily transactions between the banks in the LVTS. The Furfine algorithm picks out overnight loans by focusing on transactions sent, for example, from bank $A$ to $B$ towards the end

\footnotetext{
${ }^{3}$ Indirect participants are outside LVTS and are the clients of the direct participants.

${ }^{4}$ There are additional limits on counterparty risk imposed in the system. For more details on LVTS see Arjani and McVanel (2010)
} 
of the day (for robustness we study two different windows: 4-6:30pm, and 5-6:30pm; but we only report results for the latter) and returned from $B$ to $A$ the following day before noon for the same amount plus a mark-up equal to a rate near the Bank of Canada's target rate. We are relatively loose with the definition of 'near', allowing financial institutions to charge rates plus or minus 50 basis points from target (financial institutions that are short can borrow from the central bank at plus 25 basis points and those that are long can lend to the central bank at minus 25 basis points). This approach allows us to identify both the quantity borrowed/lent and at what price. ${ }^{5}$
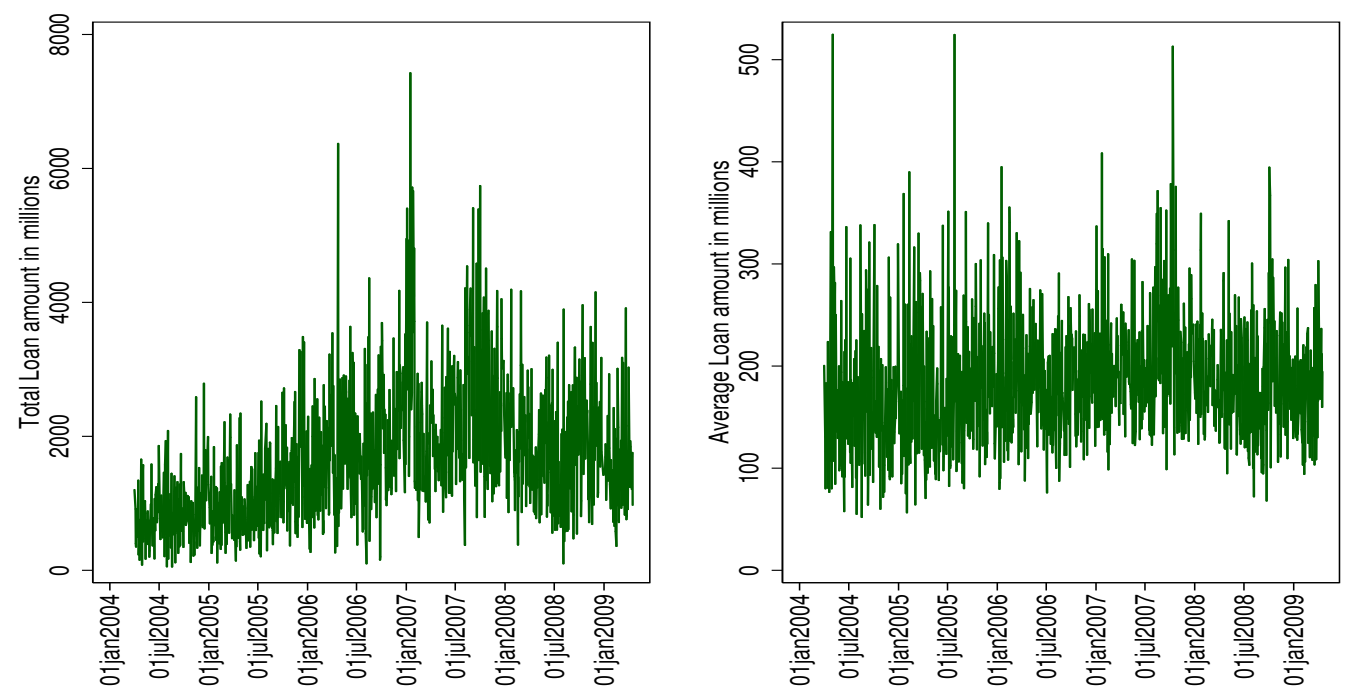

Figure 1: Loan Quantities in LVTS

Figure 1 plots both the total loan amounts and average loan size for transactions in LVTS after 5pm between April 2004 and April 2009. On the average day approximately 1.63 billion is transacted, about 184 million per financial institution. By construction the smallest loan is 50 million; the largest loan is 1.7 billion. Aside from the large spike in transactions in January 2007, the key noticeable pattern is the increase in loan amounts in the summer and fall of 2007. The sum of daily transactions in this period were consistently above $\$ 3$ billion. This coincides with the Asset-Backed Commercial

\footnotetext{
${ }^{5}$ The main issue with the Furfine algorithm is that it has the potential to identify some transactions as loans when they are indeed payments. This is particularly true when using the algorithm early in the day, or for small transactions. The situation with LVTS is less problematic than with Fedwire, which processes Euro-dollar transactions, tri-party repo legs and bank to non-fedwire institution transactions, which may or may not be considered loans. Therefore using the Furfine algorithm on LVTS transactions is less likely to lead to misclassification error. In addition, we only examine larger transactions (\$50 million or greater) late in the day, making misclassification even less likely.
} 
Paper (ABCP) crisis in Canada. ${ }^{6}$ At the time the market for non-bank issued ABCP froze and banks had to take back bank-issued ABCP on their balance sheet. By July 2007, the ABCP market was one-third of the total money market and when maturities came due and were not renewed this created substantial stress on other sources of liquidity demand. Irrespective of the freezing of the ABCP market, however, direct participants in LVTS continued lending to each other. But at what price did this lending occur?
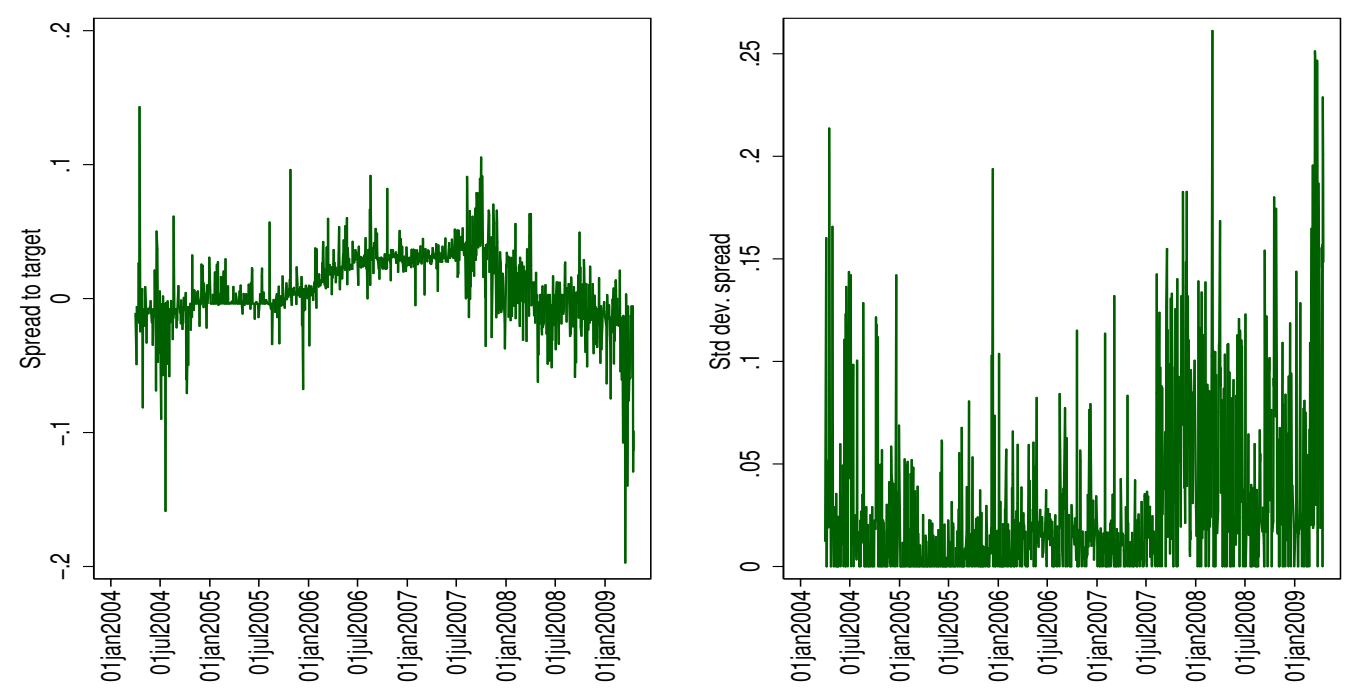

Figure 2: Loan Prices in LVTS

Figure 2 plots the average spread to the target rate and its standard deviation for transactions sent after 5pm between April 2004 and April 21, 2009. Prior to the summer of 2007, i.e. normal times, the average spread to target is approximately 1 basis point. Throughout 2007, however, financial institutions did increase the price of an overnight uncollateralized loan. Between August 9th, 2007 and October 11th, 2007 the average spread to target was about 4.7 basis points. $^{7}$ Somewhat surprisingly the spread to target post-October 2007 is 0 , and -0.6 basis points in the six weeks following the collapse of Lehman Brothers. Allen, Hortaçsu, and Kastl (2011) find that LVTS

\footnotetext{
${ }^{6} \mathrm{ABCP}$ is a package of debt obligations typically enhanced with a liquidity provision from a bank. In Canada the bank providing the liquidity only has to pay out under catastrophic circumstances and was not even triggered during the financial crisis. In addition, the regulator did not require banks to hold capital against the provision. Under these rules the market approximately doubled between 2000 and 2007 to $\$ 120$ billion.

${ }^{7}$ The start of the ABCP crisis is recognized to be August 9th (Acharya and Merrouche (2009)). The Bank of Canada held its first liquidity auction on October 12th, 2007.
} 
participants demand for term liquidity was substantial only in this period.

\subsection{Monetary policy and Liquidity policy}

Monetary policy has been implemented in Canada since 1999 through LVTS (Reid (2007), Engert, Gravelle, and Howard (2008)). At the end of the day any short or long positions in LVTS must be settled, either through interbank trades or with the central bank at a penalty rate. ${ }^{8}$ The interest rate corridor (the difference between the rate on overnight deposits and overnight loans with the central bank) is set so that banks have the right incentives to find counterparties among themselves to settle their positions before close of LVTS. The midpoint of the corridor is the interest rate that the central bank targets in its execution of monetary policy.

The symmetry of the interest rate corridor is meant to encourage trading at the target rate. Within a corridor system a central bank can increase the supply of liquidity without lowering the target rate which is bounded below by the deposit rate. Therefore a central bank operating a corridor can provide liquidity to LVTS participants (liquidity policy) without lowering nominal rates "too much" (monetary policy).

When the Bank of Canada first implemented LVTS it set settlement balances to zero, which meant it required participants to close out their long and short positions completely - that is, the central bank targeted "zero excess liquidity" during this initial period. Upon implementation of LVTS, however, there was substantial volatility in the overnight (lending) rate, with the overnight rate tending to be above the mid-point of the corridor. Therefore, in 1999, the Bank started targeting positive "settlement balances". This meant that at the end of the trading day, market participants would, in aggregate, have long positions in LVTS settlement funds. That is, some participants in LVTS would end up with deposits at the central bank at the penalty deposit rate. This served to reduce the overnight rate toward the target rate at the middle of the corridor.

Effectively, then, controlling the amount of cash settlement balances was a means for the Bank of Canada to inject liquidity into this market as needed. Liquidity and cash settlement balances are therefore used interchangeably throughout the text. In November 1999 the target amount of liquidity was set to be around $\$ 200$ million. $^{9}$ In 2001 the Bank of Canada lowered the target amount

\footnotetext{
${ }^{8}$ All LVTS participants (foreign and domestic) have access to borrowing and lending facilities.

${ }^{9}$ Liquidity is distributed among the 15 LVTS participants via a series of auctions that are also used for investing
} 


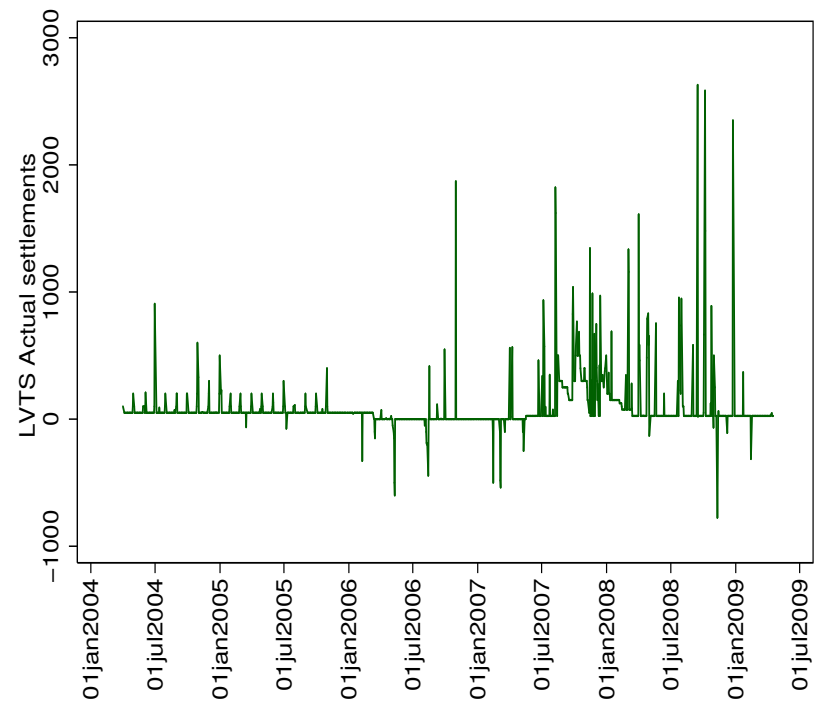

Figure 3: Actual Cash Settlement Balances in LVTS

of liquidity to $\$ 50$ million, and the volatility in the overnight rate fell until the end of 2005 . Starting in March 2006, faced with strong downward pressure on the overnight rate, the Bank of Canada implemented a low liquidity policy by reducing the target amount of liquidity balances back to zero, thereby not allowing participants to be in an aggregate long position at the end of the day. This regime continued until the summer of 2007 when, on the eve of the financial crisis, the Bank of Canada joined other central banks in injecting liquidity into the banking system. Cash settlement balances were increased to $\$ 500$ million at this point. Figure 3 presents the cash settlement balances in LVTS at the end of each day between April 2004 and April 2009. ${ }^{10}$

Since we expect these shifts in liquidity policy would naturally affect efficiency in the LVTS, our subsequent empirical analysis focuses on how efficiency and bargaining power changed across the three periods just discussed: First, April 1, 2004 to February 28, 2006, a period of stability in the Canadian interbank market, i.e. when the overnight rate did not deviate substantially and the Government of Canada's cash holdings. The Bank of Canada sometimes also uses repos. See Engert, Gravelle, and Howard (2008) for more details.

${ }^{10}$ We present actual cash balances since it conforms most closely with the model and with the timing of lending, i.e. after 5:30pm. If we were more interested in intra-day loans the settlement balances targeted at the beginning of the day by the central bank would be the variable of interest. However, these loans are more difficult to establish using the Furfine algorithm. 
persistently from the target rate. Second, March 1, 2006 to February 14, 2007, a period where the target level of liquidity in LVTS was set to zero. Third, the financial crisis: August 9, 2007 to April $20,2009$.

\section{Methodology}

We present a cooperative bargaining model of the market for overnight loans, and use it to study efficiency and bargaining power. We prefer this cooperative approach to a noncooperative (gametheoretic) model of bargaining which, as is well-known, very sensitive to the specific extensive-form which is assumed: it depends on the order in which offers are made, on the assumptions of player communication, and the information that they possess. Given that we study the volatile period surrounding the financial crisis of 2008, the assumption that a stable extensive form bargaining model is valid throughout this period would be quite strained. The crisis period is very unlikely to fit any version of known extensive-form bargaining models.

Instead of a game-theoretic model of bargaining, we apply the concept of the core to an interbank loan market. Essentially, the core is a basic "no-arbitrage" requirement; we show that it can used to investigate the bargaining power of the financial institutions in the system. We can estimate a simple measure of the bargaining power of the institutions who had a need for funds, versus those that held a positive position in the market for interbank loans.

The cooperative approach assumes that agents can make binding commitments. In contrast, a non-cooperative model would need to construct explicit commitments through repeated-game effects. Repeated games are empirically complicated because they tend to predict too little. Our approach gives a set-valued prediction (the core of the market), so we shall not predict a unique allocation of trades; but, as we shall see, the prediction is still quite sharp and useful. At the same time, for allocations which are within the core, we can naturally construct a measure of bargaining power, by looking at whether the observed allocation favors lenders or borrowers in the market more.

The market has $n$ agents, each with a net position (at the end of the day) of $\omega_{i} \in \mathbf{R}$. The central bank sets a target rate $r$. It offers each bank (collateralized) credit at the bank rate $b=r+25$, and pays the deposit rate $d=r-25>0$ on positive balances. These rates are fixed "take it or leave 
it" offers, and hence we use these as the benchmark from which to calculate bargaining power. In a sense, the central bank has the maximum bargaining power in this market, and we use its rates to calibrate the bargaining power of other agents.

We assume that $\sum_{i} \omega_{i}=0$, so that positive and negative balances in the aggregate cancel out. ${ }^{11}$ In this setup, agents have incentives to trade with each other at rates somewhere in the band.

Define a characteristic function game by setting the stand alone value for a coalition $S \subseteq N=$ $\{1, \ldots, n\}$ as:

$$
\nu(S)=\left\{\begin{array}{cl}
b \sum_{i \in S} \omega_{i} & \text { if } \sum_{i \in S} \omega_{i} \leq 0 \\
d \sum_{i \in S} \omega_{i} & \text { if } \sum_{i \in S} \omega_{i}>0
\end{array} .\right.
$$

These inequalities present the idea that the best a coalition $S$ can do is to use multilateral negotiations to pool their net positions, and then deposit (borrow) the pooled sum $\sum_{i \in S} \omega_{i}$ at the Bank at the rate $d(b)$.

The payoff to a bank is simply a number, $x_{i}$, which is the net position of that bank, $\omega_{i}$, multiplied by the bank's negotiated rates $\left(y_{i}\right)$. The core of $\nu$ is the set of rates $\left(y_{1}, \ldots, y_{n}\right)$ such that: (i) $\sum_{i \in N} y_{i} \omega_{i}=0$ (this is just an accounting identity that among all the banks net payments and outlays must cancel out); and, (ii) for all coalitions $S, \sum_{i \in S} y_{i} \omega_{i} \geq \nu(S)$. That is, any coalition must obtain a payoff exceeding its stand-alone value.

Intuitively, the core of this game is the set of rates which are "immune" to multilateral negotiations on the part of any coalition $S$ (which would result in the coalition payoff $\nu(S)$ defined in equation 1). A simpler approach is to calculate bilateral interest rates on specific loans between banks, and see how often they lie within the band $(d, b)$. We focus on the core instead because we want to look at the bank's daily operation, not at specific loans, and (more importantly) because we want to account for deals that may involve more than one bank and the central bank.

\subsection{The Core of the Interbank Market: Necessary Conditions}

We first derive necessary conditions for a set of interest rates $\left\{y_{1}, \ldots, y\right\}$ to be in the core.

1. Individual rationality requires that $y_{i} \omega_{i} \geq \nu(\{i\})$. That is: $y_{i} \geq d$ if $\omega_{i}>0$ and $y_{i} \leq b$ if

\footnotetext{
${ }^{11}$ It is easy to accommodate $\sum_{i} \omega_{i}$ of any magnitude in the analysis below, but since we calculate balances from transactions data, $\sum_{i} \omega_{i}=0$ is always satisfied automatically in our data.
} 
$\omega_{i}<0$.

2. Similarly, $\sum_{j \in N \backslash\{i\}} y_{j} \omega_{j} \geq \nu(N \backslash\{i\})$ implies the following: if $\omega_{i}>0$ then $\sum_{j \in N \backslash\{i\}} \omega_{j}=$ $\sum_{j \in N} \omega_{j}-\omega_{i}=0-\omega_{i}<0$. Therefore, $\nu(N \backslash\{i\})=-b \omega_{i}$. Hence,

$$
0-y_{i} \omega_{i}=\sum_{j \in N \backslash\{i\}} y_{j} \omega_{j} \geq \nu(N \backslash\{i\})=-b \omega_{i}
$$

which implies that $y_{i} \leq b$. Therefore

$$
b \geq y_{i} \geq d
$$

A similar argument implies that $b \geq y_{i} \geq d$ when $\omega_{i}<0$.

3. For a general coalition $S$, we require that

$$
\begin{aligned}
& \sum_{i \in S} y_{i} \omega_{i} \geq d \sum_{i \in S} \omega_{i}, \quad \text { for } \sum_{i \in S} \omega_{i}>0 \\
& \sum_{i \in S} y_{i} \omega_{i} \geq b \sum_{i \in S} \omega_{i}, \quad \text { for } \sum_{i \in S} \omega_{i}<0 .
\end{aligned}
$$

In the second inequality above, because $b>0$ (as is typically the case), the right-hand side of the inequality is negative. These two inequalities embody the intuition that a coalition which is collectively a net lender (resp. borrower) must obtain a higher payoff than lending to (resp. borrowing from) the central bank.

4. Finally, when $\sum_{i \in S} \omega_{i}=0$ we need to impose that $\sum_{i \in S} y_{i} \omega_{i} \geq 0$. This just means that a coalition in which the members' balances cancel out should not be making a negative payoff.

\subsection{A measure of bargaining power $\lambda$}

It is easy to check that the vectors of rates $(d, \ldots, d)$ and $(b, \ldots, b)$ are both in the core. ${ }^{12}$ The first is the best allocation for the debtors and the second is the best allocation for the creditors. All the allocations $\lambda(b, \ldots, b)+(1-\lambda)(d, \ldots, d)$ for $\lambda \in(0,1)$ are in the core as well. In fact, when the allocation lies on this line, or close to it, the we can interpret $\lambda$ as a measure of bargaining power

\footnotetext{
${ }^{12}$ Thus, the core is always non-empty. A necessary and sufficient condition for the non-emptiness of the core is that the game be balanced. A basic exposition of the theory is in Osborne and Rubinstein (1994).
} 


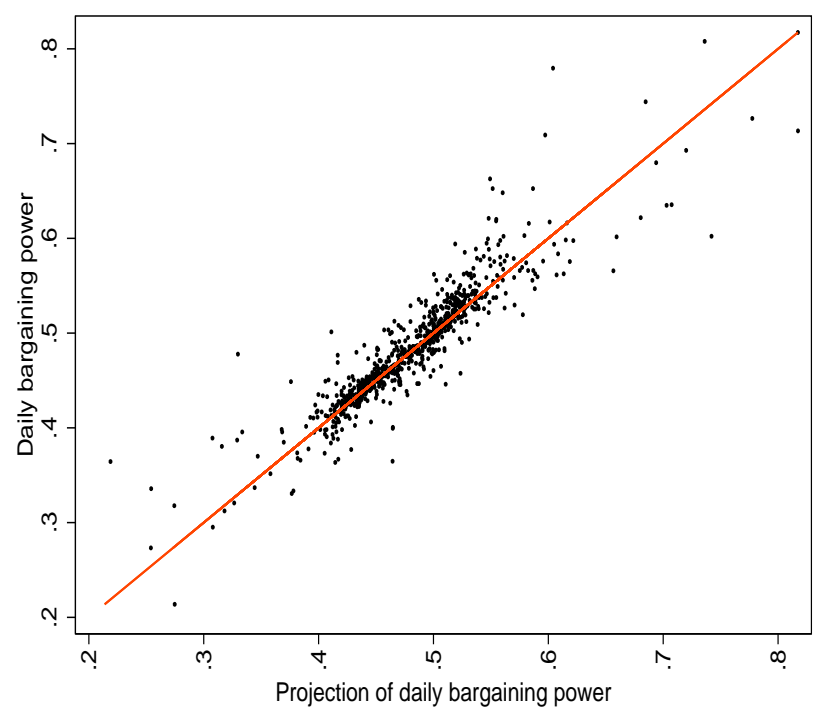

Figure 4: Goodness of Fit

for the creditors. When $\lambda \sim 1$ we obtain the core allocations that are best for the creditors; note that in this case the creditors are obtaining a deal which is similar to the "take it or leave it" offer of the central bank. It makes sense to interpret such an allocation as reflective of a high bargaining power on the side of creditors. Similarly, when $\lambda \sim 0$ we obtain the core allocations that are best for the borrowers. In this case, they are getting a similar deal to the one obtained by the central bank in its role as borrower. ${ }^{13}$

As Figure 4 illustrates, $\lambda$ provides a reasonable measure of bargaining power for the LVTS trades. In that figure, we plot (on the y-axis) the actual interest rates received by the LVTS participants, versus (on the $\mathrm{x}$-axis) the linear projection of this rate on the line segment between $(b, b, \ldots, b)$ and $(d, d, \ldots, d)$. That is, for the interest rate $y_{i t}$ received by bank $i$ on date $t$, the projected rate is $\hat{y}_{i t}=\hat{\lambda}_{t} * b+\left(1-\hat{\lambda}_{t}\right) * d$ where $\hat{\lambda}_{t}$ denotes the bargaining power measure estimated for day $t$. (Note that the projected rate $\hat{y}_{i t}$ is the same for all banks $i$ trading on day $t$, because $\lambda_{t}$ does not vary across banks.) Figure 4 shows that, for the vast majority of trades, the projected rate is quite close

\footnotetext{
${ }^{13}$ An alternative would be to look at bilateral interest rates on individual loans, and gauge bargaining power depending on whether the lender or the borrower gets a better deal. Our measure represents a way of aggregating up to a daily market-wide measure. It looks at the market outcome, and sees if it is closer to the best outcome for lenders or borrowers across the market as a whole.
} 

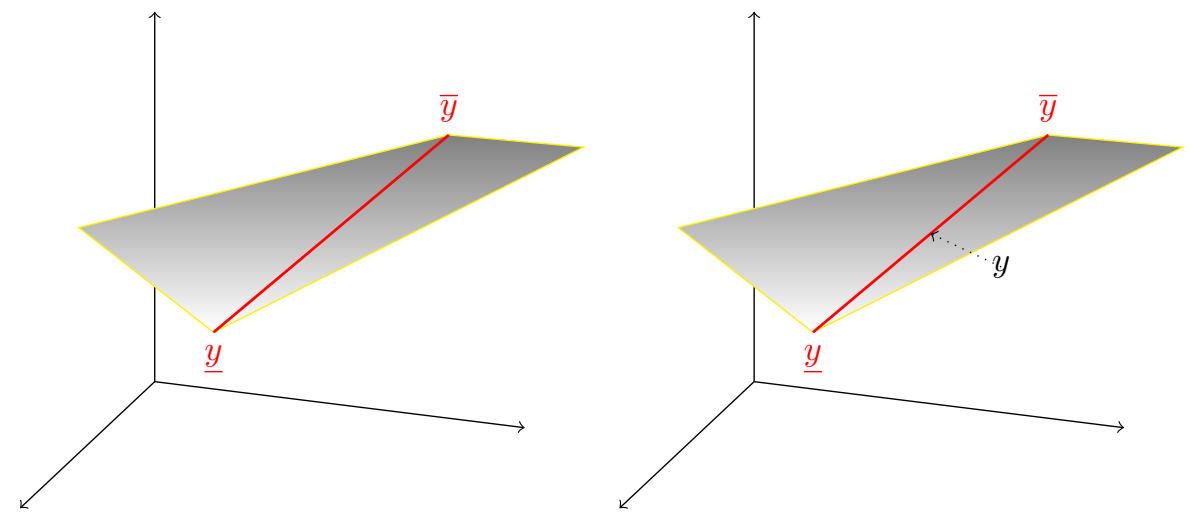

(a) The core in Example 2: $y=(d, d, d)$ and (b) An allocation $y$ projected onto the $y-\bar{y}$ $\bar{y}=(b, b, b)$.

line.

Figure 5: An illustration of Example 2.

to the actual rate. This provides reassurance that $\lambda_{t}$ serves as an adequate measure of bargaining power for this market.

\subsection{The Core of the Interbank Market: some examples}

Next, we provide several examples of the core of markets.

Example 1: Suppose that $\left|\omega_{i}\right|=1$ for all $i$. Then if $\omega_{i}=1$ and $\omega_{j}=-1$ we require $y_{i}-y_{j} \geq 0$, as $\nu(\{i, j\})=0$. Similarly, reasoning from $N \backslash\{i, j\}$ we get $y_{i}-y_{j} \leq 0$, so $y_{i}-y_{j}=0$. Then the core is exactly the allocations $\lambda *(b, \ldots, b)+(1-\lambda) *(d, \ldots d$,$) for \lambda \in(0,1)$.

Example 2: Suppose that there are three agents, and that the agents' net positions are $\left(\omega_{1}, \omega_{2}, \omega_{3}\right)=$ $(-1,-1,2)$. The core is the set of points $\left(y_{1}, y_{2}, y_{3}\right)$ that satisfy the core constraints. First, no individual agent must be able to block a core allocation, hence all the points in the core are in $[d, b]^{3}$. Second, we obtain that $2 y_{3}-y_{1} \geq d$ and $2 y_{3}-y_{2} \geq d$ for coalitions $\{1,3\}$ and $\{2,3\}$, respectively. Finally, the coalition of the whole requires that $-y_{1}-y_{2}+2 y_{3}=0$. The latter condition, together with $\left(y_{1}, y_{2}, y_{3}\right) \in[d, b]^{3}$, imply the conditions for coalitions $\{1,3\}$ and $\{2,3\}$. Thus the inequalities $2 y_{3}-y_{1} \geq d$ and $2 y_{3}-y_{2} \geq d$ are redundant.

We illustrate the core in Figure 5. Allocations are points in $\Re^{3}$, as there are three agents in the example. The shaded region is the set of points that satisfy the core constraints. Geometrically, it 
Table 1: Sample trades

\begin{tabular}{cccc} 
Borrower & Lender & Amount & Interest Rate(rel. to target rate) \\
\hline $\mathrm{B}$ & $\mathrm{E}$ & 1.00 & -0.0077 \\
$\mathrm{E}$ & $\mathrm{K}$ & 1.29 & -0.0581 \\
$\mathrm{~K}$ & $\mathrm{~A}$ & 1.00 & 0.0022 \\
\hline
\end{tabular}

Table 2: Banks positions and prices

\begin{tabular}{ccc}
\hline Bank & $\omega$ & $y$ \\
\hline $\mathrm{A}$ & 1.00 & 0.0022 \\
$\mathrm{~B}$ & -1.00 & -0.0077 \\
$\mathrm{E}$ & -0.29 & -0.2319 \\
$\mathrm{~K}$ & 0.29 & -0.2660 \\
\hline
\end{tabular}

consists of the points on the plane $-y_{1}-y_{2}+2 y_{3}=0$ that have all their coordinates larger than $d$ and smaller than $b$. The half-line $\lambda(b, b, b)+(1-\lambda)(d, d, d)$ is indicated in red in the figure and is a proper subset of the core. There are then core allocations, such as $(b, d,(b+d) / 2)$, which are not symmetric.

Figure 5(b) also illustrates how we calculate bargaining power. A point $y$ is projected onto the line $\lambda(b, b, b)+(1-\lambda)(d, d, d)$. The value of $\lambda$ corresponding to the projection is a measure of the bargaining power of the creditors in the bargaining process that resulted in the allocation $y$.

Example 3: Finally, we consider one illustrative example of an actual allocation from the LVTS. On this particular day, there were four banks (labeled A,B,E,K) involved, and a total of three trades. Because we have normalized the target rate to zero, the values of $(b, d)$ are $(0.25,-0.25)$.

Based on these trades, we can construct the bank-specific balances and prices $\left(\omega_{i}, y_{i}\right)$. For concreteness, consider bank E, which is both a lender (to B) and a borrower (from K). The value of $\omega$ for $\mathrm{E}$ is just its net position, which is $-0.29=1-1.29$. Correspondingly, its price $y$ is the trade-weighted interest rate:

$$
y_{E}=\frac{(1.0) *(-0.0077)+(-1.29) *(-0.0581)}{1-1.29}=-0.2319
$$

Similarly, Table 2 contains the positions and prices for all four banks.

For these four banks, there are $2^{4}-1=15$ coalitions to check. The different possible coalitions 
Table 3: Inequalities

\begin{tabular}{cc} 
Coalition & Satisfies inequalities? \\
\hline$\{A, B, E, K\}$ & Yes \\
$\{B, E, K\}$ & Yes \\
$\{A\}$ & Yes \\
$\{A, E, K\}$ & Yes \\
$\{B\}$ & Yes \\
$\{A, B, E\}$ & Yes \\
$\{K\}$ & No \\
$\{A, B, K\}$ & Yes \\
$\{E\}$ & Yes \\
$\{B, E\}$ & Yes \\
$\{A, K\}$ & Yes \\
$\{E, K\}$ & No \\
$\{A, B\}$ & Yes \\
$\{A, E\}$ & Yes \\
$\{B, K\}$ & Yes \\
\hline
\end{tabular}

are listed in Table 3 along with whether they satisfy the core inequalities defined in section 3 above.

First, note that, by construction, $\sum_{i=A, B, E, K} \omega_{i}=0$ and $\sum_{i=A, B, E, K} y_{i} \omega_{i}=0$. Second, we can see by examining the positions in Table 1 for the reasons that the three coalitions fail to satisfy the inequalities. In the data, bank $\mathrm{K}$ is a net lender of 0.29 , at a price of -0.2660 , which is lower than the rate of $d=-0.25$ it could have obtained by depositing the net amount of 0.29 at the Bank of Canada. Also, the coalition of $\{E, K\}$ has a net zero balance, but a payoff of $\sum_{i=E, K} \omega_{i} y_{i}=0.29 *(0.2319-0.2660)<0$, which is negative. They could have done better if $\mathrm{K}$ had not lent the amount of 0.29 to $\mathrm{E}$ at any rate, in which case their payoff would have been zero.

On the other hand, consider the coalition $\{A, B, E\}$, with a net position of $\sum_{i=A, B, E} \omega_{i}=-0.29$. The payoff for this coalition at the observed allocation is $\sum_{i=A, B, E} \omega_{i} y_{i}=0.0771$ which exceeds $b *(-0.29)=-0.0725$. That is, on net, this coalition, despite having a negative net balance, obtains a positive net payoff, which is of course preferable to borrowing 0.29 from the Bank of Canada at the rate $b=0.25$. This also implies that the banks who are borrowing from the coalition $\{A, B, E\}$ - here it is just bank $\mathrm{K}$ - must be paying too much for borrowing; this is indeed the case, as the singleton coalition $\{K\}$ violates the inequalities. 


\section{Empirical results}

In the dataset, we observe $\left(\omega_{i t}, y_{i t}\right)$ for banks $i=1, \ldots, n$ and days $t=1, \ldots, T$. This corresponds to the outstanding balance at bank $i$ at the end of day $t$ and the interest rate that bank $i$ either paid (if $\omega_{i t}<0$ ) or earned (if $\omega_{i t}>0$ ) by borrowing or lending in LVTS. Given the prices and quantities from LVTS, our approach allows us to solve for the percentage of transactions that are violations of core (denoted by $a v$ ), as well as the bargaining power $(\lambda)$ of lenders relative to borrowers on each day.

\subsection{Interbank Market Efficiency: Are Trades in the Core?}

Necessary conditions for the day $t$ participants settlement interest rates $\left\{y_{i t}\right\}_{i=1}^{n}$ to be in the core of the game are the inequalities (2) and (3) sketched above. Figure 6 plots the degree to which each day's allocation violates the core inequalities. It presents a plot of the percent of coalitions on each day that violate the core inequalities. On most days the vast majority of overnight loans do not violate our core equilibrium restrictions and are therefore deemed efficient. However, on approximately 54 per cent of days there is at least one core restriction that is violated: at least one coalition could do better by trading among themselves. There are only 9.4 per cent of days where more than 10 per cent of trades violate the core inequality restrictions. The percent of inefficient coalitions, however, increases in the fall of 2007 and throughout most of 2008.

One may want to know by how much a coalition could gain. Since, as we emphasized above, the core restrictions are essentially no-arbitrage conditions imposed on coalitions of banks, one way to quantify the severity of the violations is to copute how much a coalition could gain if it were to deviate from the observed allocation, thereby exploiting the arbitrage opportunity implied by the violation of the core inequalities. If the gain is small it might not be worthwhile for lenders and borrowers to negotiate a better allocation. We can think of the gain as the distance of the allocation to the core, or as the cost of the bargaining outcome relative to full efficiency. We calculate the cost by measuring the distance between the allocation $x$ at any give date and the closest core allocation. To determine this distance we need to solve the problem of minimizing $\| x-z||$, which is the Euclidean

distance between the observed allocation $x$ and any alternative allocation $z$ which lies within the 


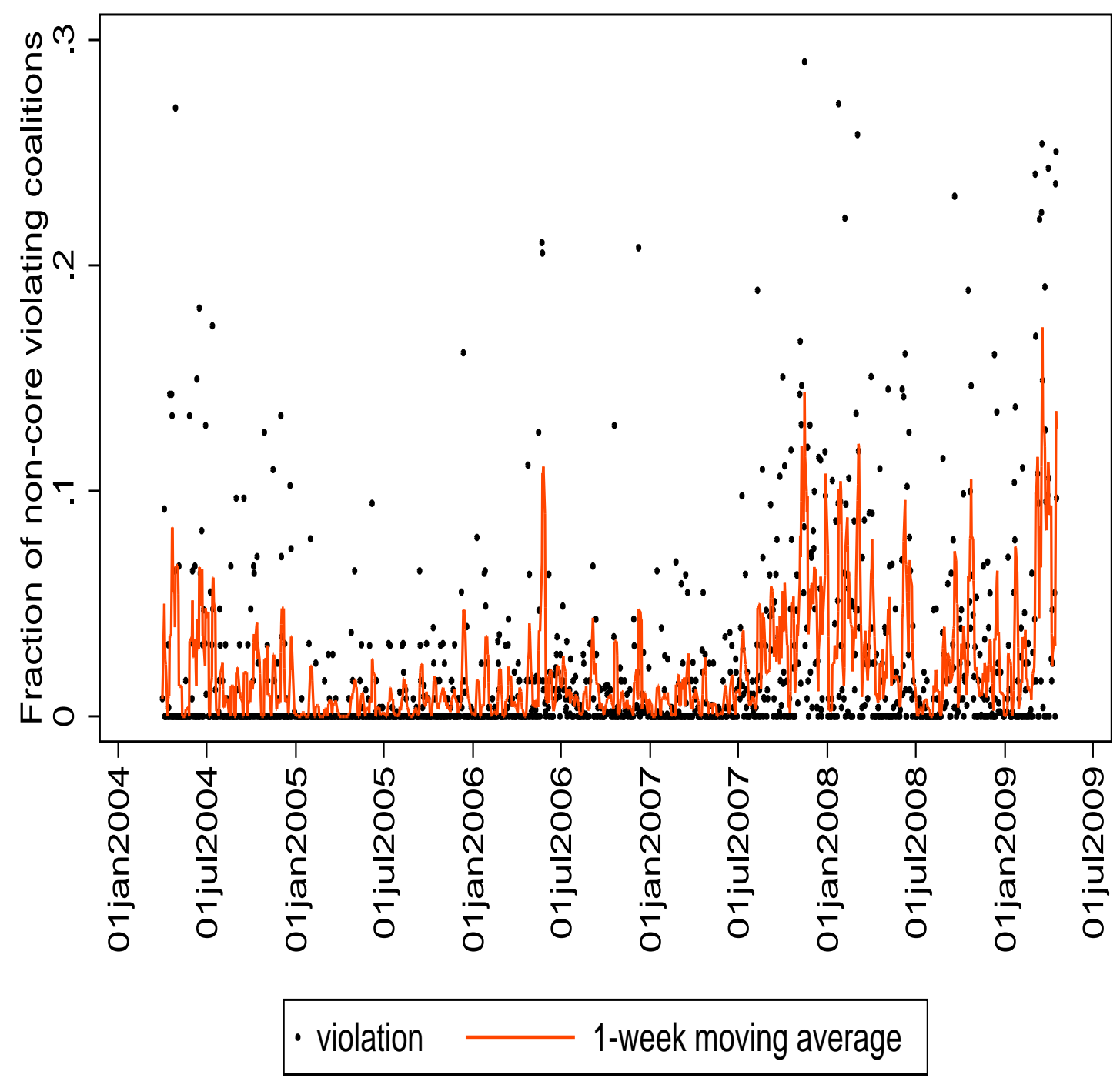

Figure 6: Fraction of non-core violating coalitions 


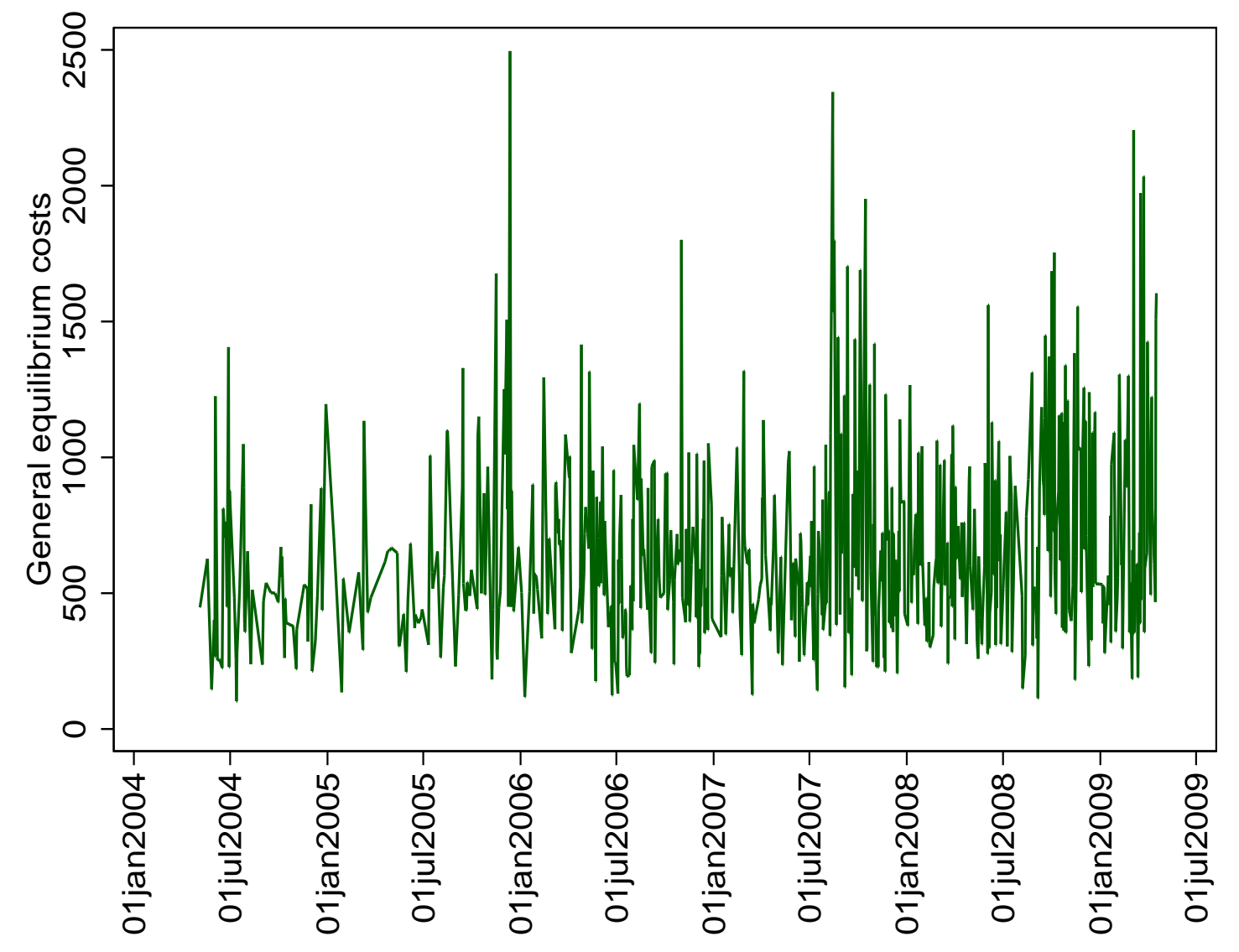

Figure 7: Costs of Overnight Loan Outside the Core

core.

The overnight costs are plotted in Figure 7. The average cost of correcting a violating allocation is $\$ 636$ and the maximum is $\$ 2495$. These costs are larger than those presented elsewhere, eg. in Chapman, McAdams, and Paarsch (2007). ${ }^{14}$ To give some context, note that the dollar value of these costs translates roughly to two basis points. ${ }^{15}$ While at first glance this may seem small when compared to other, more volatile, markets, it is actually large in this instance where the

\footnotetext{
${ }^{14}$ Chapman, McAdams, and Paarsch (2007) studies the bidding behavior of these same participants in daily 4:30pm auctions for overnight cash, and find that, while there are persistent violations of best-response functions in these auctions, the average cost of these violations is very small, only a couple of dollars.

${ }^{15}$ This is found by multiplying the average number of trades by the average loan size and finding the dollar cost of one basis point for this amount.
} 
standard deviation of the overnight rate around the overnight target is one basis point. Therefore, our estimates suggest that the expected costs due to inefficiency dwarf the expected risk in this market.

\subsection{Bargaining Power}

We construct a measure of bargaining power for lenders relative to borrowers for each day, and then evaluate how it evolves over time. Specifically, we project each daily allocation onto the line $\lambda(b, \ldots, b)+(1-\lambda)(d, \ldots d$,$) . This gives us an estimate of \lambda$ for each day.

Figure 8 plots the bargaining power of the lenders. When $\lambda$ equals 1 the lender has all the bargaining power and when it is 0 the borrower has all the bargaining power. The bargaining power of lenders and borrowers is roughly equal between April 2004 and January 2006. Then it moves in favor of lenders until January 2008. Lenders' bargaining power is the greatest from August to October of 2007 following the closure of two hedge funds on August 9, 2007 by BNP Parisbas and statements by several central banks, including the Bank of Canada, that they would inject overnight liquidity. ${ }^{16}$ Starting in January 2008 the bargaining power of borrowers is greater than that of the lenders. We analyze the determinants of bargaining power in section 4.3.

\subsection{Regression Results}

This section explores how $a v$ and $(1-\lambda)$, i.e., the borrowers' bargaining power, are correlated with bank and LVTS characteristics. We also analyze how costs are related to violations and bargaining power.

\subsubsection{Explanatory Variables}

Table 4 presents summary statistics of our variables of interest and explanatory variables for three sub-samples: (i) April 1, 2004 to February 28, 2006, (ii) March 1, 2006 to February 14, 2007, and

\footnotetext{
${ }^{16}$ On August 9th, 2007 the Bank of Canada issued a statement that they were ready to provide liquidity. The ECB injected $€ 95$ billion overnight.
} 


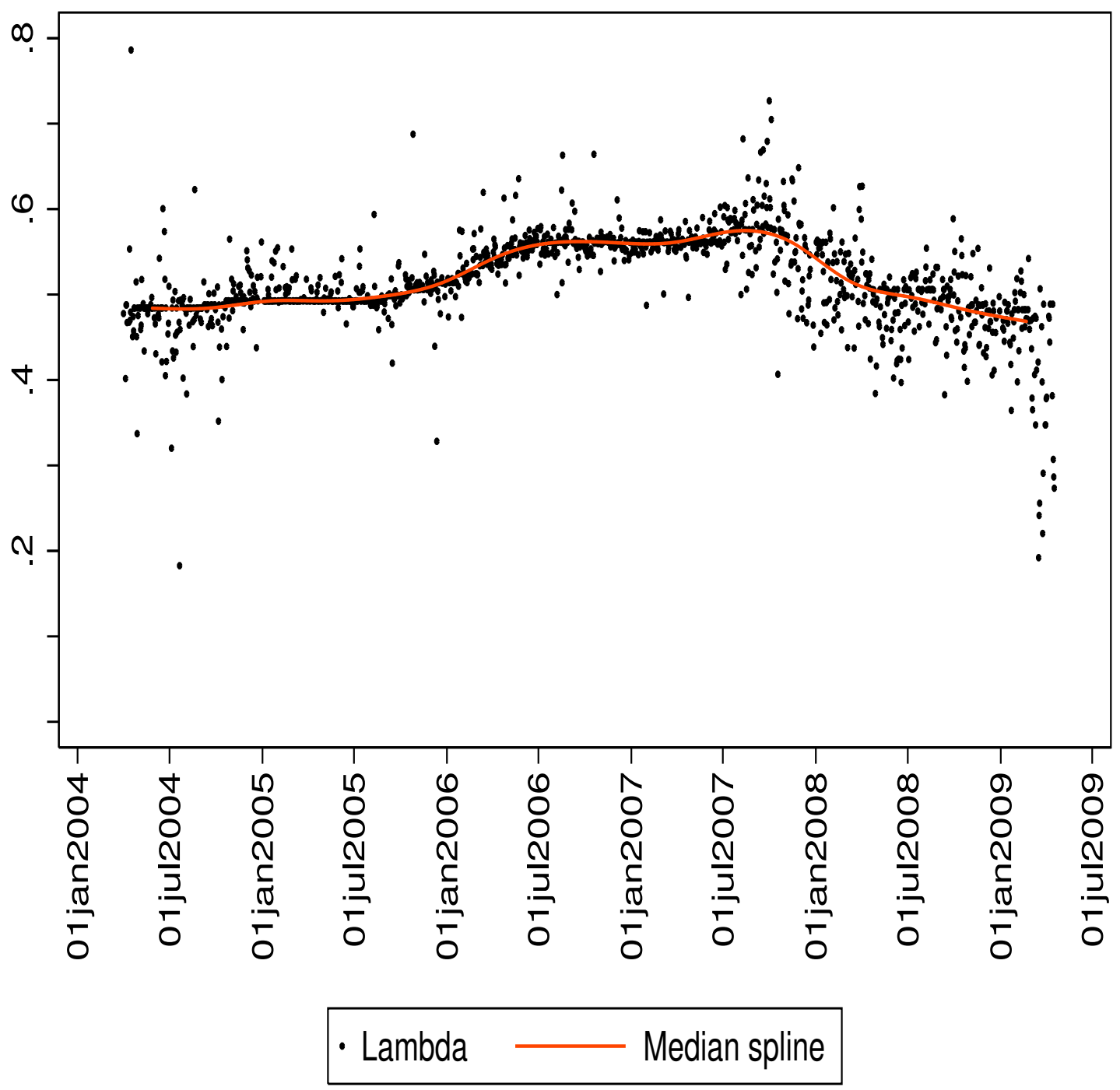

Figure 8: Bargaining Power of the Lender 
(iii) August 9, 2007 to April 20, 2009. The samples are chosen based on important demarcations of events. April 1, 2004 is when our sample begins. The final sample date, April 20, 2009, was chosen because it is the day before the Bank of Canada instituted an interest rate policy at the effective lower bound, making analysis after this day more complicated. From March 1, 2006 to February 14, 2007, the Bank of Canada targeted cash settlement balances to be zero, i.e. did not injecting liquidity (Reid (2007)). Finally, the financial crisis commenced on August 9th, 2007, so the final sub-sample is the economic crisis period.

Our analysis includes bank risk measures such as credit default swap (CDS) spreads, Merton's (1974) distance-to-default $(D D)$, balance sheet measures of risk such as liquidity over assets $(L / A)$, and wholesale funding over assets $(W F / A) \cdot{ }^{17} D D$ measures the market value of a financial institutions assets relative to the book value of its liabilities. An increase in $D D$ means a bank is less likely to default. Furthermore, institutions with high liquidity ratios are considered less risky and those with high wholesale funding ratios are considered more risky. We also include an indicator variable for whether or not a financial institution accessed the Bank of Canada's term liquidity facility during the crisis (see Allen, Hortaçsu, and Kastl (2011)), or the Canadian government's Insured Mortgage Purchase Program (IMPP). ${ }^{18}$

Market trend or risk variables include the spread between the one month Canadian Dealer Offered Rate and one month Overnight Indexed Swap rate $(C D O R-O I S)$, total number of lenders, borrowers and trades in LVTS on each day, and actual cash settlement balances in LVTS. The one month $C D O R$ is similar to one month $L I B O R$ in that it is indicative of what rate surveyed banks are willing to lend to other banks for one month. OIS is an overnight rate and is based on expectations of the Bank of Canada's overnight target rate. The spread is a default risk premium. We interpret increases in the $C D O R$ - OIS spread as increases in default risk of the banking industry generally and not related to any specific institution such as is the case for DD, CDS, L/A, or WF/A.

As discussed in section 2.2, cash settlement balances are important since they are actively man-

\footnotetext{
${ }^{17}$ Wholesale funding is defined as fixed term and demand deposits by deposit-taking institutions plus banker acceptances plus repos.

${ }^{18}$ The IMPP is a government of Canada mortgage buy-back program aimed at adding liquidity to banks' balance sheets. On October 16, 2008 the government announced it would buy up to $\$ 25$ billion of insured mortgages from Canadian banks. This represented about $8.5 \%$ of the banking sectors on-balance sheet insured mortgages. On November 12, 2008 this was raised to $\$ 75$ billion, and subsequently raised to $\$ 125$ billion on January $28,2009$.
} 
aged by the Bank of Canada. ${ }^{19}$ To manage minor frictions and offset transactions costs the Bank typically leaves excess balances of $\$ 25$ million in the system. Figure 3 shows this to be the case. The figure also shows that balances can be negative (that is, the Bank of Canada left the system short), which they were 15 times between March 2006 and February 2007. Figure 3 also shows that the Bank injected liquidity substantially above $\$ 25$ million for almost the entire time between the summer of 2007 and early 2009.

Another potentially important factor determining the fraction of efficient coalitions and bargaining power is pledgable collateral. Each day LVTS participants pledge collateral to the system in case of default. At the end of the day participants who have long or net zero positions withdraw their collateral, possibly using it in the overnight repo market. Participants that are short must borrow from the central bank at unfavorable rates and pledge collateral. Depending on the amount of collateral pledged to the LVTS intraday, and the size of their short position, a participant might not have sufficient collateral already pledged with the central bank for an overnight loan. ${ }^{20}$ If this is the case, a participant negotiating for an overnight loan is in a relatively weak bargaining position with the long participant. The long participant knows that if the short participant does not have sufficient collateral to borrow from the central bank they can charge a premium for lending unsecured. The mean loan to collateral value presented in Table 4, however, suggests collateral is not an important concern.

\footnotetext{
${ }^{19}$ There are occasions when the Bank of Canada cannot achieve its desired target level of settlement balances (see Engert, Gravelle, and Howard (2008).

${ }^{20}$ This could occur because of the collateral savings present in the survivor pay tranche of LVTS.
} 


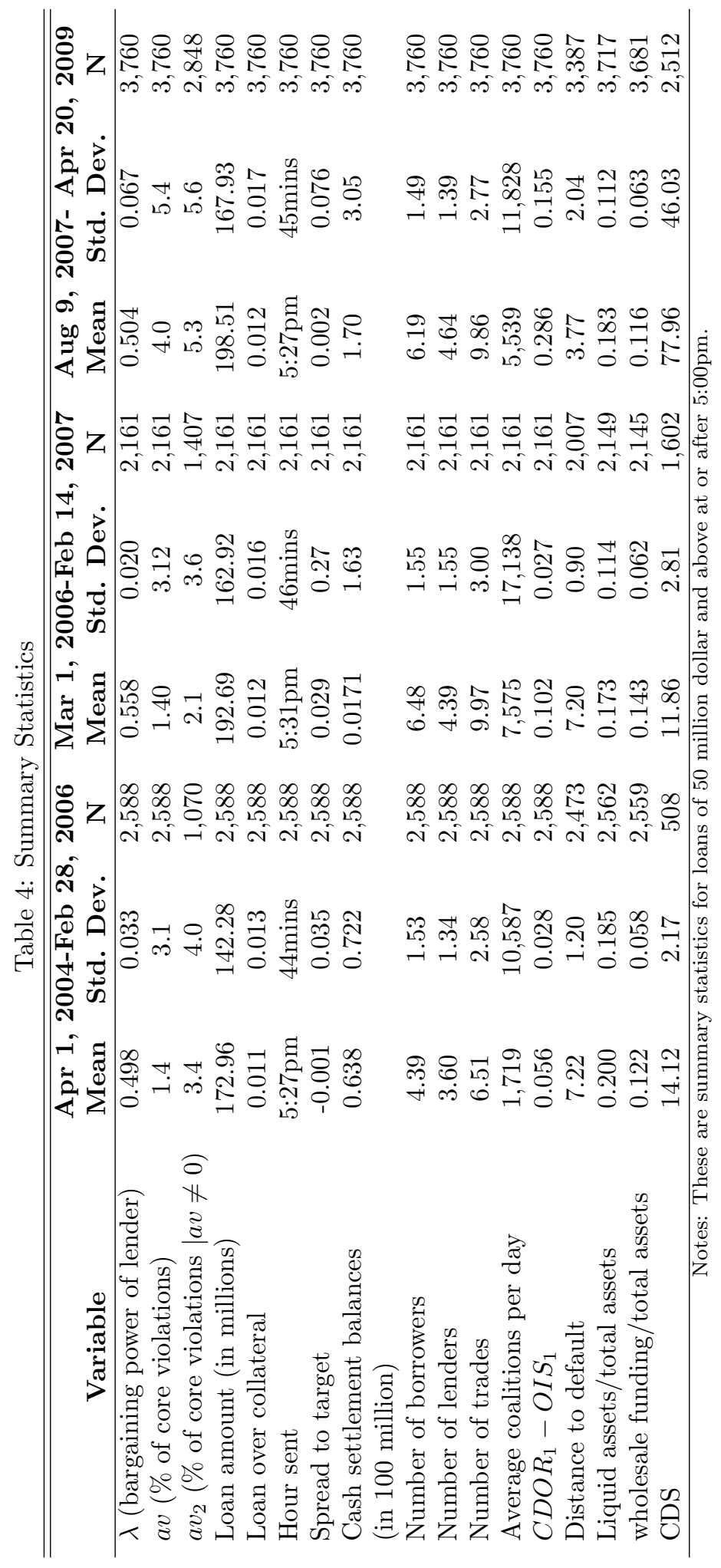




\subsubsection{Determinants of Violations of Core Inequalities}

We consider Poisson regressions for the percent of violations in a day and probit regressions for whether or not there was a violation on a given day. We present results for our three sub-samples, where an observation is a day in one of the following periods: (i) April 1, 2004 to February 28, 2006,

(ii) March 1, 2006 to February 14, 2007, and (iii) August 9, 2007 to April 20, 2009.

The explanatory variables used to explain violations of the core restrictions (equations (2) and (3)) are at the market level. We include $C D O R-O I S$, as well as the number of borrowers, lenders, and trades. We also include actual cash settlement balances in the system. ${ }^{21}$ The results are presented in Table 5. The percentage of violations we observe in the data are decreasing in the $C D O R-O I S$ spread and increasing the number of participants. These findings are reasonable as they first suggests that multilateral bargaining becomes more focused as market risk increases and therefore it is more likely that the bargaining mechanism results in an efficient outcome. The opposite is true when there are a large number of participants. The more players involved in the game, the greater the percentage of violations, which suggests there is more likely to be an inefficient outcome when a larger group tries to negotiate than when there is a smaller group. Finally, we find that liquidity injections by the central bank is correlated with an increase in core violations. The results in column (1) of Table 5 suggest that this effect is not the result of the crisis but from the liquidity injections themselves. ${ }^{22}$ Liquidity injections, therefore, appear to increase the probability of inefficiency as well as the number of inefficient allocations. Consistent with Goodfriend and King (1988), the financial market is efficient at allocating credit without the central bank holding large cash settlement balances.

\footnotetext{
${ }^{21}$ In regressions not reported here we also analyzed the importance of operational risk. This risk includes the occasional system failure due to process, human error,etc. Operational risk also excludes 6 days where the trading period was extended beyond 6:30pm. The average extension was 45 minutes. Internal operational risk measures were not significant in explaining core violations or bargaining power.

${ }^{22}$ This is somewhat in contrast to Freixas, Martin, and Skeie (2012) who show that a central bank which controls both the level of the interbank rate and the amount of liquidity injected can achieve efficiency in the interbank market. Our empirical results imply that regardless of what level (i.e. when it is constant and decreasing) the interbank rate is, increasing liquidity decreases efficiency. That is, we not only find a correlation between liquidity injections (high cash settlement balances) and the percentage of core violations during the crisis, but also during the first pre-crisis sub-period, when the Bank of Canada was actively injecting liquidity into the interbank market.
} 
Table 5: Regressions on Violations of Core Inequality Restrictions

The dependent variable in columns (1)-(3) is $a v$, which is the percentage of violations of the core restrictions per day. The dependent variable in columns (4)-(6) is $I(a v \neq 0) .{ }^{a} p<0.01,{ }^{b} p<0.05,{ }^{c} p<0.1$. Standard errors are in parentheses.

\begin{tabular}{|c|c|c|c|c|c|c|}
\hline \multirow[b]{3}{*}{ VARIABLES } & (1) & $(2)$ & $(3)$ & $(4)$ & $(5)$ & $(6)$ \\
\hline & \multicolumn{3}{|c|}{ Percent of core violations } & \multicolumn{3}{|c|}{ Violation $(\mathrm{Y} / \mathrm{N})$} \\
\hline & $\begin{array}{l}\text { Apr } 12004- \\
\text { Feb } 282006\end{array}$ & $\begin{array}{l}\text { Mar } 12006- \\
\text { Feb } 142007\end{array}$ & $\begin{array}{l}\text { Aug } 92007- \\
\text { Apr } 202009\end{array}$ & $\begin{array}{l}\text { Apr } 12004- \\
\text { Feb } 282006\end{array}$ & $\begin{array}{l}\text { Mar } 12006- \\
\text { Feb } 142007\end{array}$ & $\begin{array}{l}\text { Aug } 92007- \\
\text { Apr } 202009\end{array}$ \\
\hline \multirow[t]{2}{*}{ Lagged violations } & $0.0295^{b}$ & $0.0868^{a}$ & $0.0382^{a}$ & & & \\
\hline & $(0.0119)$ & $(0.0120)$ & $(0.00374)$ & & & \\
\hline \multirow[t]{2}{*}{1 month CDOR minus OIS } & $-16.37^{a}$ & 0.798 & $-0.584^{a}$ & $-6.247^{b}$ & -2.170 & 0.281 \\
\hline & $(1.826)$ & $(2.227)$ & $(0.182)$ & $(2.477)$ & $(3.301)$ & $(0.485)$ \\
\hline \multirow[t]{2}{*}{ Number of lenders } & $0.454^{a}$ & $0.190^{a}$ & $0.315^{a}$ & $0.357^{a}$ & $0.373^{a}$ & $0.344^{a}$ \\
\hline & $(0.0466)$ & $(0.0589)$ & $(0.0230)$ & $(0.0807)$ & $(0.0930)$ & $(0.0732)$ \\
\hline \multirow{2}{*}{ Number of borrowers } & $0.470^{a}$ & 0.0534 & $0.200^{a}$ & $0.337^{a}$ & $0.180^{b}$ & $0.164^{b}$ \\
\hline & $(0.0491)$ & $(0.0556)$ & $(0.0253)$ & $(0.0806)$ & $(0.0886)$ & $(0.0746)$ \\
\hline \multirow[t]{2}{*}{ Number of trades } & $-0.267^{a}$ & 0.0302 & $-0.128^{a}$ & 0.0338 & 0.0264 & 0.0588 \\
\hline & $(0.0400)$ & $(0.0377)$ & $(0.0169)$ & $(0.0631)$ & $(0.0669)$ & $(0.0532)$ \\
\hline \multirow{2}{*}{$\begin{array}{l}\text { Actual LVTS cash balances } \\
\text { (100 millions) }\end{array}$} & $0.0773^{c}$ & 0.0294 & $0.0393^{a}$ & 0.170 & 0.00613 & $0.0547^{b}$ \\
\hline & $(0.0439)$ & $(0.0312)$ & $(0.00690)$ & $(0.122)$ & $(0.0721)$ & $(0.0272)$ \\
\hline \multirow[t]{2}{*}{ Constant } & $-1.027^{a}$ & $-1.565^{a}$ & -0.191 & $-3.015^{a}$ & $-2.346^{a}$ & $-2.497^{a}$ \\
\hline & $(0.174)$ & $(0.373)$ & $(0.139)$ & $(0.313)$ & $(0.526)$ & $(0.379)$ \\
\hline Observations & 463 & 231 & 397 & 469 & 240 & 416 \\
\hline
\end{tabular}




\subsubsection{Determinants of Bargaining Power}

For bargaining power we estimate a linear time-series regression with a long list of explanatory variables: these include the number of lenders, number of borrowers, total number of transactions, actual LVTS cash settlement balances (liquidity injections) in the system, one month CDOR-OIS spread, cash allocations from the Bank of Canada liquidity facility (term PRA), IMPP allocations, distance-to-default, CDS spreads, liquidity to assets at month $t-1$, wholesale funding to assets at month $m-1$, and borrower fixed effects. In addition, we also include a lagged dependent variable $\left(\lambda_{t-1}\right)$ to accommodate the persistence of bargaining power. 
Table 6: Bargaining Regressions - Full Sample

\begin{tabular}{|c|c|c|c|c|}
\hline \multicolumn{5}{|l|}{ VARIABLES } \\
\hline$(1-\lambda)_{t-1}$ & $\begin{array}{c}0.411^{a} \\
(0.0415)\end{array}$ & $\begin{array}{c}0.513^{a} \\
(0.0430)\end{array}$ & $\begin{array}{c}0.378^{a} \\
(0.0428)\end{array}$ & $\begin{array}{c}0.375^{a} \\
(0.0431)\end{array}$ \\
\hline Percent of core violations & $\begin{array}{c}0.159^{a} \\
(0.0614)\end{array}$ & $\begin{array}{c}0.193^{a} \\
(0.0638)\end{array}$ & $\begin{array}{c}0.180^{a} \\
(0.0635)\end{array}$ & $\begin{array}{c}0.188^{a} \\
(0.0635)\end{array}$ \\
\hline Number of lenders & $\begin{array}{c}-0.0860 \\
(0.148)\end{array}$ & $\begin{array}{l}-0.107 \\
(0.154)\end{array}$ & $\begin{array}{c}0.115 \\
(0.146)\end{array}$ & $\begin{array}{l}0.0832 \\
(0.146)\end{array}$ \\
\hline Number of borrowers & $\begin{array}{l}-0.306 \\
(0.485)\end{array}$ & $\begin{array}{l}-0.202 \\
(0.510)\end{array}$ & $\begin{array}{l}-0.118 \\
(0.577)\end{array}$ & $\begin{array}{l}-0.384 \\
(0.580)\end{array}$ \\
\hline Number of trades & $\begin{array}{l}-0.202^{b} \\
(0.0927)\end{array}$ & $\begin{array}{l}-0.200^{b} \\
(0.0994)\end{array}$ & $\begin{array}{c}-0.233^{b} \\
(0.0989)\end{array}$ & $\begin{array}{c}-0.203^{b} \\
(0.0983)\end{array}$ \\
\hline Actual LVTS cash balances (100 millions) & $\begin{array}{l}0.00549 \\
(0.0828)\end{array}$ & $\begin{array}{l}-0.0254 \\
(0.0875)\end{array}$ & $\begin{array}{l}-0.0183 \\
(0.0819)\end{array}$ & $\begin{array}{l}-0.0195 \\
(0.0838)\end{array}$ \\
\hline 1 month CDOR minus OIS & $\begin{array}{c}-6.139^{a} \\
(1.438)\end{array}$ & $\begin{array}{l}-1.573 \\
(1.322)\end{array}$ & $\begin{array}{c}-5.573^{a} \\
(1.431)\end{array}$ & $\begin{array}{r}-5.320^{a} \\
(1.450)\end{array}$ \\
\hline I(Term PRA allocation at $\mathrm{t}-1>0)$ & $\begin{array}{c}0.897 \\
(0.652)\end{array}$ & $\begin{array}{l}2.126^{a} \\
(0.721)\end{array}$ & $\begin{array}{l}0.408 \\
(0.673)\end{array}$ & $\begin{array}{c}0.210 \\
(0.631)\end{array}$ \\
\hline I(IMPP allocation at $\mathrm{t}-1>0)$ & $\begin{array}{c}0.00662 \\
(2.200)\end{array}$ & $\begin{array}{c}1.376 \\
(2.139)\end{array}$ & $\begin{array}{l}-0.617 \\
(2.046)\end{array}$ & $\begin{array}{l}-0.979 \\
(2.079)\end{array}$ \\
\hline Distance to default & $\begin{array}{c}-0.846^{a} \\
(0.119)\end{array}$ & & & $\begin{array}{l}-0.406 \\
(0.258)\end{array}$ \\
\hline Liquidity/assets at m-1 & $\begin{array}{c}1.425 \\
(3.172)\end{array}$ & $\begin{array}{c}-5.169^{c} \\
(3.070)\end{array}$ & $\begin{array}{c}0.878 \\
(4.720)\end{array}$ & $\begin{array}{c}2.490 \\
(4.854)\end{array}$ \\
\hline Loan amount/borrower's LVTS collateral & $\begin{array}{l}-31.69 \\
(26.63)\end{array}$ & $\begin{array}{c}-69.44^{b} \\
(27.68)\end{array}$ & $\begin{array}{l}1.438 \\
(32.50)\end{array}$ & $\begin{array}{c}5.159 \\
(33.37)\end{array}$ \\
\hline Wholesale funding/assets at m-1 & $\begin{array}{l}-5.086 \\
(8.992)\end{array}$ & $\begin{array}{c}-31.45^{a} \\
(8.718)\end{array}$ & $\begin{array}{l}-8.525 \\
(11.20)\end{array}$ & $\begin{array}{l}-2.205 \\
(11.41)\end{array}$ \\
\hline CDS & & & $\begin{array}{c}0.0516^{a} \\
(0.00647)\end{array}$ & $\begin{array}{l}0.0288^{c} \\
(0.0172)\end{array}$ \\
\hline Constant & $\begin{array}{l}37.43^{a} \\
(3.141)\end{array}$ & $\begin{array}{l}30.89^{a} \\
(3.326)\end{array}$ & $\begin{array}{l}29.01^{a} \\
(3.089)\end{array}$ & $\begin{array}{l}31.48^{a} \\
(3.505)\end{array}$ \\
\hline $\begin{array}{l}\text { Observations } \\
R^{2} \\
\text { Borrower FE }\end{array}$ & $\begin{array}{c}1208 \\
0.498 \\
\checkmark \\
\end{array}$ & $\begin{array}{c}1208 \\
0.464 \\
\checkmark \\
\end{array}$ & $\begin{array}{c}862 \\
0.589 \\
\checkmark \\
\end{array}$ & $\begin{array}{c}862 \\
0.603 \\
\checkmark \\
\end{array}$ \\
\hline
\end{tabular}


We present two tables of results. We report the full sample results in Table 6 and sub-sample results in Table 7. Table 6 column (4) includes the full set of variables but because some of the risk variables are highly collinear in columns (1)-(3) we present slight deviations, dropping one or more of these risk factors in each specification. Overall, we find that the bargaining power of the borrower is persistent, increasing in the number of core violations (inefficiency), and decreasing in the number of trades. The negative coefficient on the CDOR - OIS spread suggests that bargaining power is decreasing in market risk. ${ }^{23}$ There are negative correlations between the borrower's distance-todefault and bargaining power and their wholesale funding and bargaining power. At the bank-level, therefore, an increase in risk is correlated with less bargaining power. However, we find a positive correlation between CDS spreads and bargaining power, suggesting the opposite effect of the other risk factors - that an increase in risk is correlated with an increase in bargaining power.

Table 7 presents estimates of the regression, broken down by the three sub-samples as in the previous regressions in Table 5 above. Very striking contrasts across sub-periods emerge in these specifications - especially during the financial crisis period. In the "normal" periods 2004-2006 and 2006-2007, the coefficients attached to the risk measures suggest that riskier institutions enjoy less bargaining power. However, during the financial crisis period (post-2007), bargaining power becomes negatively correlated with distance-to-default and positively correlated with CDS spreads and wholesale funding exposure. Thus riskier institutions enjoyed more bargaining power during these troubled times.

Too big to fail? What are possible explanations? One possibility is that mark-to-market accounting and bank interconnectedness means that some banks were concerned with their positions vis-á-vis the riskier banks (e.g. Bond and Leitner (2010)). The short-term cost of lending to a risky bank at a discount to an interconnected bank might be far less than the cost of having to mark down assets linked to a failed institution. Another reason is that market participants may simply want to prevent government intervention. The cost of government intervention might be deemed too high for many participants, given the future regulatory burden that would come with the failure of a Canadian financial institution would likely be high. Note, that unlike the risk variables, the coefficient on the collateral variable is insignificant in every period. Although the Bank of Canada

\footnotetext{
${ }^{23} \mathrm{~A}$ further interpretation is that a borrower's bargaining power is decreasing as financial stress of the system increases.
} 
relaxed its collateral policies, during the crisis there was no significant effect on bargaining power. This is probably because the collateral constraints are far from binding for LVTS participants.

Next, we explore this possibility that financial institutions were lending to riskier institutions out of self-interest by looking at the probabilities that banks' positions in the interbank market can switch from the lending side one day to the borrowing side the next day. Table 8 presents summary statistics of these transition probabilities for both borrowers transitioning to lenders $\left(\operatorname{Pr}\left(X^{\prime}>0 \mid X<0\right)\right)$ and lenders transitioning to borrowers $\left(\operatorname{Pr}\left(X^{\prime}<0 \mid X>0\right)\right)$. The top panel presents transitions using the full set of data while panels 2-4 present information on sub-periods. The median probability in the first case is approximately $68 \%$ where the median probability in the latter case is approximately $45 \%$. This indicates that the incidence that a particular institution is a "lender" or "borrower" is not persistent, and suggests that lenders may, in fact, be willing to support or subsidize troubled borrowers out of concern that they might find themselves in a similar situation in the future. ${ }^{24}$ These results are also in line with Carlin, Lobo, and Viswanathan's (2007) "episodic illiquidity" model, in which repeated interaction sustains firms' provision of "apparent liquidity" to each other.

The summary statistics from the sub-periods suggests there is not a great deal of change in persistence over time, except for the probability of transitioning from lender to borrower is smaller at the lower quantile in period 3. Overall the lack of any significant change in the transition probabilities suggests that bargaining power increased for borrowers in general, and not for any particular set of borrowers. A careful look at the bank-level transition probabilities, not presented here, does not reveal overwhelming evidence to suggest any particular borrower received preferential treatment.

Another reason for the concern of an individual bank failure is that entry into the Canadian banking system is regulated. The result is an oligopolistic market where banks can exploit monopoly rent. The failure of one bank might have opened the door for the entry of new players into the market, something that the existing banks would not be favorable to. It is therefore plausible that the banks who were relatively better off could have offered better terms to the most troubled banks during the crisis. This interpretation is in the long tradition of the theory of regulation presented in Becker

\footnotetext{
${ }^{24}$ Such reciprocal relationships among financial institutions has been documented elsewhere by Ashcraft and Duffie (2007) as well as in the popular press, cf. the importance placed on relationships among U.S. investment banks during the collapse of Long-Term Capital Management in 1998 and the more recent financial crisis.
} 
(1983) and Becker (1985).

Table 8: Transition Probabilities

\begin{tabular}{|c|c|c|c|c|c|c|}
\hline & Minimum & 1st Quartile & Median & Mean & 3rd Quartile & Maximum \\
\hline \multicolumn{7}{|c|}{ Full Sample } \\
\hline $\operatorname{Pr}\left(X^{\prime}>0 \mid X<0\right)$ & 0.37 & 0.56 & 0.68 & 0.69 & 0.86 & 0.96 \\
\hline $\operatorname{Pr}\left(X^{\prime}<0 \mid X>0\right)$ & 0.00 & 0.20 & 0.45 & 0.40 & 0.60 & 0.77 \\
\hline \multicolumn{7}{|c|}{ Period 1: April 1, 2004 - Feb 28, 2006} \\
\hline $\operatorname{Pr}\left(X^{\prime}>0 \mid X<0\right)$ & 0.33 & 0.50 & 0.70 & 0.69 & 0.87 & 1.0 \\
\hline $\operatorname{Pr}\left(X^{\prime}<0 \mid X>0\right)$ & 0.00 & 0.22 & 0.39 & 0.40 & 0.66 & 0.72 \\
\hline \multicolumn{7}{|c|}{ Period 2: March 1, 2006 - Feb 14, 2007} \\
\hline $\operatorname{Pr}\left(X^{\prime}>0 \mid X<0\right)$ & 0.31 & 0.54 & 0.64 & 0.68 & 0.87 & 0.95 \\
\hline $\operatorname{Pr}\left(X^{\prime}<0 \mid X>0\right)$ & 0.00 & 0.17 & 0.45 & 0.40 & 0.63 & 0.82 \\
\hline \multicolumn{7}{|c|}{ Period 3: August 9, 2007 - April 20, 2009} \\
\hline $\operatorname{Pr}\left(X^{\prime}>0 \mid X<0\right)$ & 0.28 & 0.50 & 0.63 & 0.66 & 0.87 & 1.0 \\
\hline $\operatorname{Pr}\left(X^{\prime}<0 \mid X>0\right)$ & 0.00 & 0.06 & 0.41 & 0.37 & 0.65 & 0.73 \\
\hline
\end{tabular}

Notes: $\operatorname{Pr}\left(X^{\prime}>0 \mid X<0\right)$ denotes the probability an FI is a lender today conditional on that FI being a borrower the last time they were in the overnight market. $\operatorname{Pr}\left(X^{\prime}<0 \mid X>0\right)$ denotes the probability of an FI being a borrower today conditional on that FI being a lender the last time they were in the overnight market.

\section{Economic Significance of Results}

Given the results from the regressions above, especially the evidence supporting a (weak) "too big to fail" story, we next quantify the size of these effects. First, consider a two-standard deviation decrease in a bank's distance-to-default, which implies an increase in this bank's riskiness as a borrower. If we use the estimated coefficient in column (6) of Table 7 (1.951) - for the pre-crisis period - this leads to an $8.86 \%$ decrease in bargaining power. By construction, there is a linear relationship between the bargaining power measure $\lambda$ and the interest rate $y$; specifically, a movement from $\lambda=0$ to $\lambda=1$ corresponds to the 50 basis point movement from the bank rate $b$ to the deposit rate $d$. Hence, each percentage point decrease in bargaining power for the borrower corresponds to a half basis point increase in the implied interest rate. Therefore, the $8.86 \%$ decrease in bargaining power here corresponds to a 4.4 basis point increase in the interest rate faced by the borrowers.

In contrast, during the crisis period, we find that the same decrease in distance-to-default leads to an increase in borrower bargaining power of $9.78 \%$ (using the point estimate 2.155 ) - this was the TBTF results that we highlighted earlier. This corresponds to a 4.9 basis point decrease in the 
interest rate faced by borrowers. Evaluated at the average overnight loan size of $\$ 190$ million, this implies that lending banks reduced interest payments for risky borrowers during the crisis period by an amount of $\$ 259(=(0.00049 / 360) * \$ 190$ mill $)$. This is roughly equal to $1.6 \%$ of the average cost of an overnight loan (assuming the sample average overnight rate of $3.16 \%$ ).

Similarly, calculations can be done with the other risk measures used in the bargaining regressions. Using the wholesale funding variable, we find that, during the crisis period, a two-standard deviation increase in this variable would lead to a $7.32 \%$ increase in bargaining power, corresponding to a $3.66 \%$ decrease in the interest rate. This implies that, on average, lenders "cut some slack" for risky borrowers by an amount of $\$ 187.40$ during the crisis.

To highlight the magnitudes of these effects, we perform a counterfactual exercise in which we use the second-period (pre-crisis) regression coefficients, coupled with the observed loans in the third period, to predict what bargaining power would have been in the third period, in the absence of the TBTF results in the third period regressions. These counterfactual bargaining power measures are presented in Figure 9. The top line in this graph presents the counterfactual values of $\lambda$. Obviously, this line trends upward over time, reaching the upper bound of 1 near the end of the sample, indicating that, in the absence of the TBTF effects, bargaining power would have shifted almost entirely to lenders between August 2007 and February 2009.

For comparison, the actual bargaining weights for the crisis-period loans, computed using the third-period regression coefficients, are also presented in the graph. The divergence between the actual and counterfactual results is remarkable: the actual bargaining weights steadily become more favorable to the borrowers, as the crisis proceeds.

To put this in monetary terms, we plot, in Figure 10, the "costs" of the TBTF effects, in terms of the difference in interest payments which borrowers would have had to pay if their bargaining power followed the counterfactual path during the crisis, as compared to the actual path. Corresponding to the results in Figure 9, we find that these costs increase steadily over the crisis period. A cost of $\$ 10,000$ represents $60 \%$ of the average cost of an overnight loan at the sample average target rate of $3.16 \%$. Measured this way, the effects of TBTF on bargaining are substantial. 


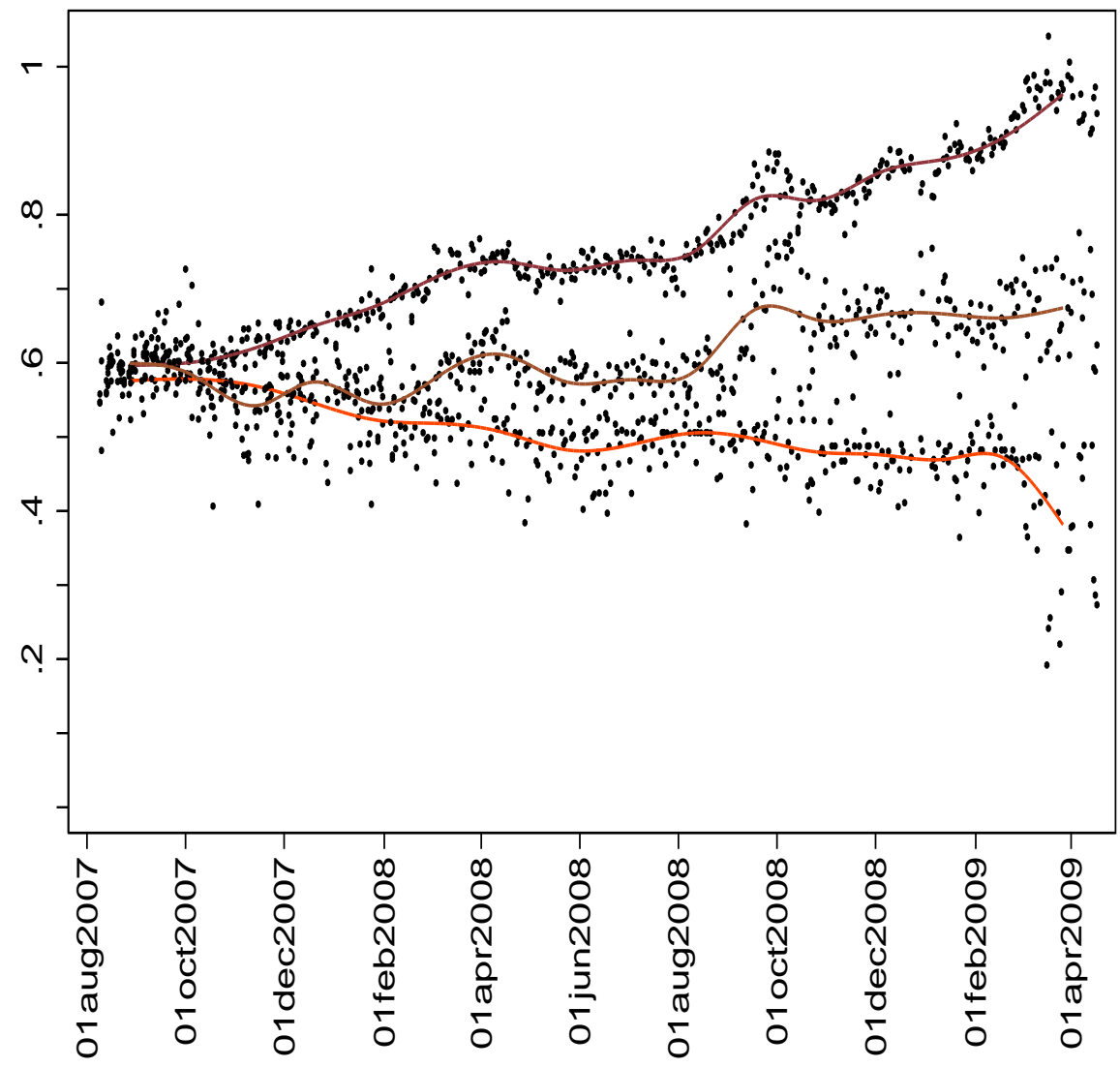

Figure 9: Actual versus counterfactual bargaining power for crisis-period loans

Top line: counterfactual bargaining weights $(\lambda)$ using second-period regression coefficients; Middle line: counterfactual bargaining weights $(\lambda)$ using first-period regression coefficients; Bottom line: actual bargaining weights $(\lambda)$ using third-period regression coefficients. 


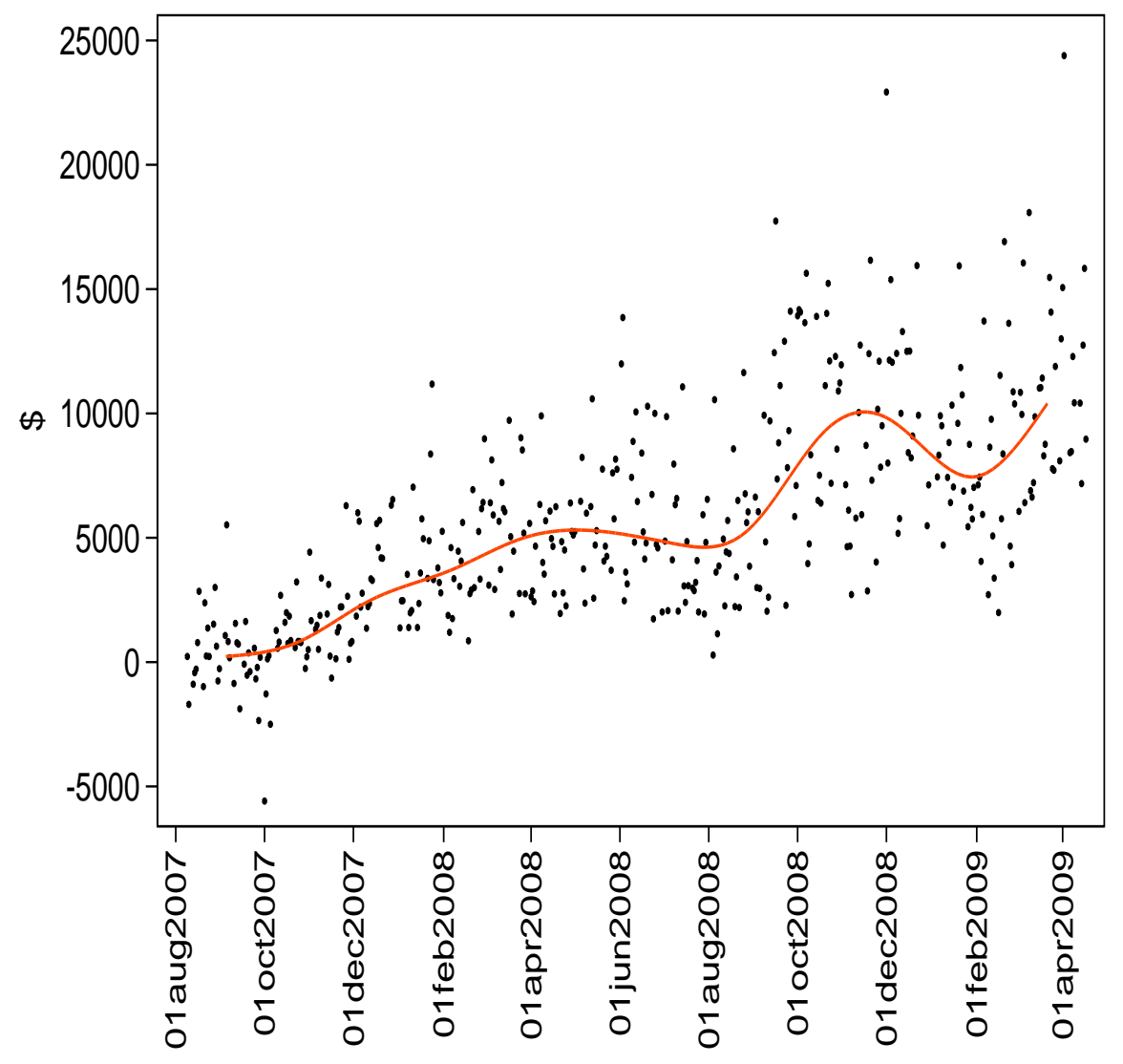

Figure 10: Costs of TBTF

This is a graph of the difference in the second-period counterfactual bargaining power and the actual bargaining power multiplied by the average loan size on each day and the one-day interest cost, i.e. $50 \mathrm{bps} / 360$. 


\section{Conclusion}

In this paper we examine efficiency and bargaining power in the Canadian interbank loan market. This market, however, is complicated. The players are engaged in an imperfect competition game in which their actions are restricted by trading conventions making it difficult to characterize the equilibrium of such a game, which is a prerequisite to any analysis of bargaining and efficiency. Instead of modeling the multilateral trading environment in detail, we instead impose a very general and classical equilibrium concept: that of the core. This simply imposes a type of ex-post no-arbitrage condition on the observed outcomes.

We study efficiency and bargaining power of financial institutions in the Large Value Transfer System (LVTS) in Canada. Our results indicate that while the interbank market in Canada is fairly efficient, there is a systemic inefficiency that is persistent through our sample. Importantly, the efficiency of the system deteriorates with the liquidity interventions of the central bank. This result is in line with the views put forth by Goodfriend and King (1988) on the efficiency of the interbank market.

While we find that bargaining power is about equal between lenders and borrowers throughout the sample, during the financial crisis there was a shift in bargaining power favoring borrowers. Regressions confirm that as counterparty risk increased during the financial crisis, the riskier borrower banks were able to obtain better rates. There are a number of possible explanations, however, our findings are most consistent with a "weak" version of the too-big-to-fail (TBTF) hypothesis whereby banks within the Canadian overnight market continued to lend to risky counterparties despite the increasing risk in the market. The main hypothesis put forth is that banks are tightly interconnected, which we confirm using borrower-to-lender transition probabilities. A more speculative view is that financial institutions acted to conserve the existing market structure rather than risk the possibility of one institution defaulting and the survivor's facing more stringent regulation.

In ongoing work, we plan to explore the extent to which the repeated and dynamic interactions among the banks underly this result. 


\section{References}

Acharya, V., D. Gromb, and T. Yorulmazer (2012). Imperfect competition in the inter-bank market for liquidity as a rationale for central banking. American Economic Journal: Macro 4, $184-217$.

Acharya, V. and O. Merrouche (2009). Precautionary hoarding of liquidity and inter-bank markets: Evidence from the sub-prime crisis.

Afonso, G., A. Kovner, and A. Schoar (2011). Stressed, not frozen: The federal funds market in the financial crisis. Journal of Finance 66, 1109-1139.

Afonso, G. and R. Lagos (2011). Trade dynamics in the market for federal funds. mimeo.

Allen, J., A. Hortaçsu, and J. Kastl (2011). Crisis management: Analyizing default risk and liquidity demand during financial stress. mimeo.

Arjani, N. and D. McVanel (2010). A primer on Canada's large value transfer system. Bank of Canada technical note.

Ashcraft, A. and D. Duffie (2007). Systemic illiquidity in the federal funds market. American Economic Review 97, 221-225.

Bech, M., J. Chapman, and R. Garratt (2010). Which bank is the "central" bank? Journal of Monetary Economics 57(3), 352-363.

Becker, G. S. (1983). A theory of competition among pressure groups for political influence. Quarterly Journal of Economics 98, 371-400.

Becker, G. S. (1985). Public policies, pressure groups, and dead weight costs. Journal of Public Economics 28, 329-347.

Bond, P. and Y. Leitner (2010). Market run-ups, market freezes, and leverage. Federal Reserve Bank of Philadelphia Working Paper No. 10-36.

Carlin, B., M. Lobo, and S. Viswanathan (2007). Episodic liquidity crisis: Cooperative and predatory trading. Journal of Finance 62, 2235-2274.

Chapman, J., D. McAdams, and H. Paarsch (2007). Bounding best-response violations in discriminatory auctions with private values. mimeo. 
Duffie, D. (2012). Dark Markets: Asset Pricing and Information Transmission in Over-theCounter markets. Princeton University Press.

Duffie, D. and N. Gârleanu (2005). Over-the-counter markets. Econometrica 73, 1815-1844.

Duffie, D., N. Gârleanu, and L. Pedersen (2007). Valuation in over-the-counter markets. Review of Economic Studies 20, 1865-1900.

Engert, W., T. Gravelle, and D. Howard (2008). The implementation of monetary policy in canada. Bank of Canada discussion paper No. 2008-9.

Flannery, M. (2010). What to do about TBTF? mimeo.

Freixas, X., A. Martin, and D. Skeie (2012). Bank liquidity, interbank markets, and monetary policy. Review of Financial Studies 25, 2655-2692.

Furfine, C. (1999). The microstructure of the federal funds market. Financial Markets, Institutions, and Instruments 8, 24-44.

Goodfriend, M. and R. King (1988). Financial dergulation, monetary policy, and central banking. Federal Reserve Bank of Richmond Economic Review, 3-22.

Gromb, D. and D. Vayanos (2010). Limits of arbitrage. Annual Review of Financial Economics 2, $251-75$.

Hendry, S. and N. Kamhi (2009). Uncollateralized overnight lending in Canada. Applied Financial Economics, 869-880.

Ho, T. and A. Saunders (1985). A micro model of the federal funds market. Journal of Finance 40, 2977-988.

Krugman, P. (2010). Financial crisis 101. New York Times Op-Ed.

Merton, R. (1974). On the pricing of corporate debt: The risk structure of interest rates. Journal of Finance 2, 449-470.

O'Hara, M. and W. Shaw (1990). Deposit insurance and wealth effects: The value of being "too big to fail". Journal of Finance 45, 1587-1600.

Osborne, M. and A. Rubinstein (1994). A Course in Game Theory. MIT Press. 
Reid, C. (2007). The Canadian overnight market: Recent evolution and structural changes. Bank of Canada Review, Spring 2007.

Rochet, J.-C. and J. Tirole (1996). Interbank lending and systemic risk. Journal of Money, Credit and Banking 28, 733-762.

Sorkin, A. (2009). Too Big to Fail. Viking Adult.

Whitsell, W. (2006). Interest rate corridors and reserves. Journal of Monetary Economics 53, $1177-1195$. 